\title{
Preliminary Demonstration Reactor Point Design for the Fluoride Salt- Cooled High-Temperature Reactor
}

Approved for public release. Distribution is unlimited.
A. Qualls
B. Betzler
N. Brown
J. Carbajo
M. Greenwood
R. Hale
T. Harrison
J. Powers
K. Robb
J. Terrell

November 2015 


\title{
DOCUMENT AVAILABILITY
}

Reports produced after January 1, 1996, are generally available free via US Department of Energy (DOE) SciTech Connect.

\section{Website http://www.osti.gov/scitech/}

Reports produced before January 1, 1996, may be purchased by members of the public from the following source:

\author{
National Technical Information Service \\ 5285 Port Royal Road \\ Springfield, VA 22161 \\ Telephone 703-605-6000 (1-800-553-6847) \\ TDD 703-487-4639 \\ Fax 703-605-6900 \\ E-mail info@ntis.gov \\ Website http://www.ntis.gov/help/ordermethods.aspx
}

Reports are available to DOE employees, DOE contractors, Energy Technology Data Exchange representatives, and International Nuclear Information System representatives from the following source:

Office of Scientific and Technical Information

PO Box 62

Oak Ridge, TN 37831

Telephone 865-576-8401

Fax 865-576-5728

E-mail reports@osti.gov

Website http://www.osti.gov/contact.html

This report was prepared as an account of work sponsored by an agency of the United States Government. Neither the United States Government nor any agency thereof, nor any of their employees, makes any warranty, express or implied, or assumes any legal liability or responsibility for the accuracy, completeness, or usefulness of any information, apparatus, product, or process disclosed, or represents that its use would not infringe privately owned rights. Reference herein to any specific commercial product, process, or service by trade name, trademark, manufacturer, or otherwise, does not necessarily constitute or imply its endorsement, recommendation, or favoring by the United States Government or any agency thereof. The views and opinions of authors expressed herein do not necessarily state or reflect those of the United States Government or any agency thereof. 
Reactor and Nuclear Systems Division

\title{
PRELIMINARY DEMONSTRATION REACTOR POINT DESIGN FOR THE FLUORIDE SALT-COOLED HIGH-TEMPERATURE REACTOR
}
A. Qualls
B. Betzler
N. Brown
J. Carbajo
M. Greenwood
R. Hale
T. Harrison
J. Powers
K. Robb
J. Terrell

Date Published: November 2015

Prepared by

\author{
OAK RIDGE NATIONAL LABORATORY \\ Oak Ridge, TN 37831-6283 \\ managed by \\ UT-BATTELLE, LLC \\ for the \\ US DEPARTMENT OF ENERGY \\ under contract DE-AC05-00OR22725
}





\section{CONTENTS}

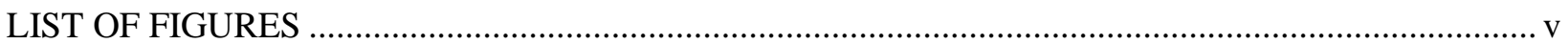

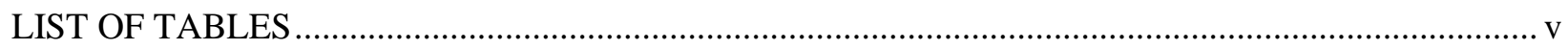

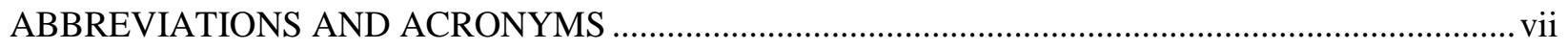

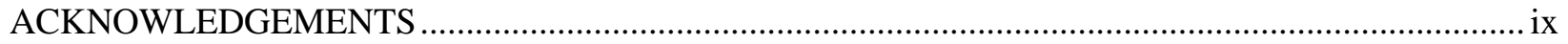

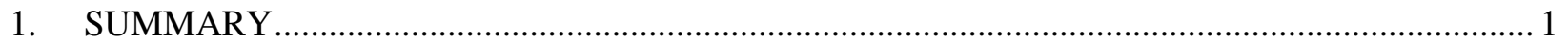

2. OBJECTIVES AND MOTIVATION FOR CONCEPT SELECTION …...................................... 5

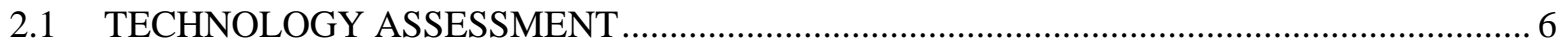

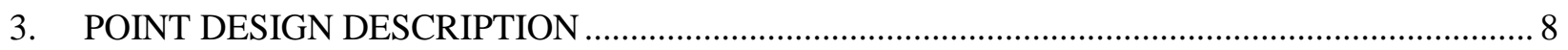

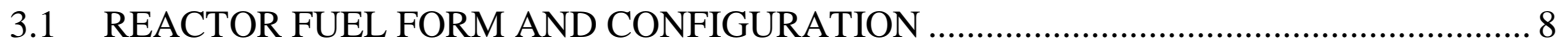

3.2 REACTOR PHYSICS OF AN EXAMPLE CORE CONFIGURATION ............................... 11

3.3 THERMAL-HYDRAULIC CALCULATIONS …................................................................ 13

3.4 PRIMARY SYSTEM SALT COOLANT AND TRITIUM MANAGEMENT........................ 19

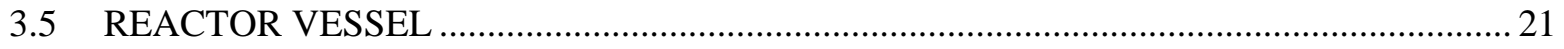

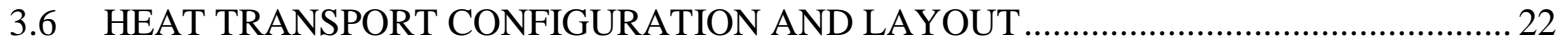

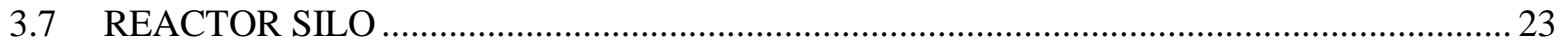

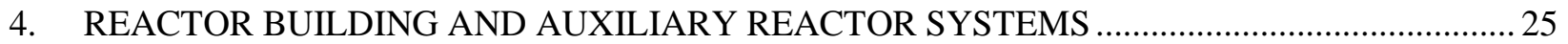

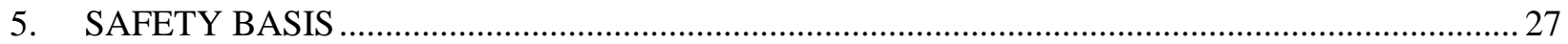

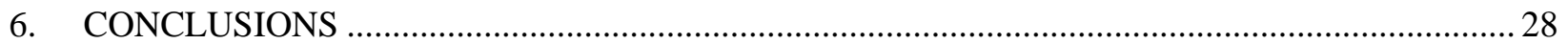

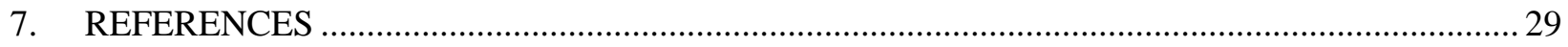

APPENDIX A. DESIGN SCORING METHODOLOGY …................................................................ A-1 



\section{LIST OF FIGURES}

Fig. 1. FHR DR demonstrates features of several promising FHR concepts.......................................... 2

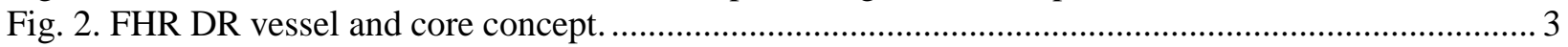

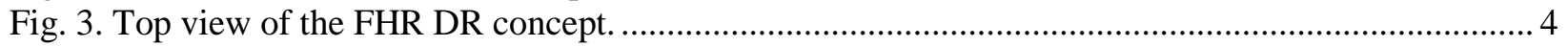

Fig. 4. Nuclear renewable hybrid energy system (Bragg-Sitton, 2014)................................................ 6

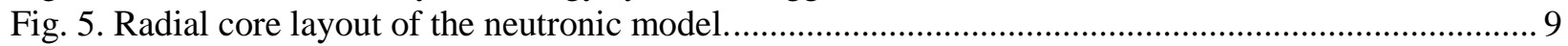

Fig. 6. View of a lower support plate of a fuel block assembly............................................................. 10

Fig. 7. Distribution of coolant and fueled channels within a FHR DR prismatic block. ......................... 10

Fig. 8. Single-batch core $\mathrm{k}_{\text {eff }}$ and complete void worth for an example core configuration. ...................... 11

Fig. 9. Thermal neutron flux contours (blue shades) in the FHR DR at BOC (left) and EOC

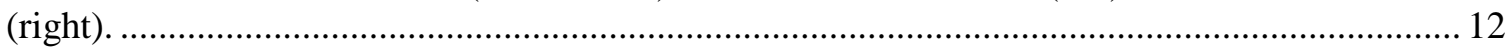

Fig. 10. COMSOL model and calculated temperatures in an average fuel block.................................... 13

Fig. 11. Calculated temperatures in an average fuel block. .................................................................. 14

Fig. 12. Calculated temperatures in the fuel and in the graphite $-1 / 6$ section. ....................................... 14

Fig. 13. RELAP5-3D nodalization employed for the complete reactor system......................................... 16

Fig. 14. RELAP5-3D calculated coolant temperatures after a LOFF with use of the passive

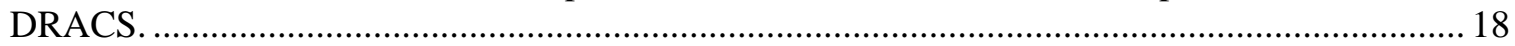

Fig. 15. RELAP5-3D calculated flows through the two DRACS (passive and active)............................. 19

Fig. 16. Elevation view of the FHR DR showing the reactor core within the vessel................................. 20

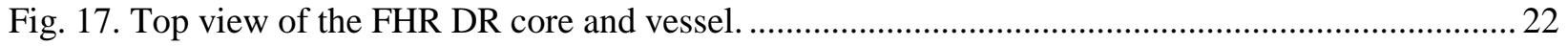

Fig. 18. View of primary system piping within the AHTR reactor building (a similar approach is

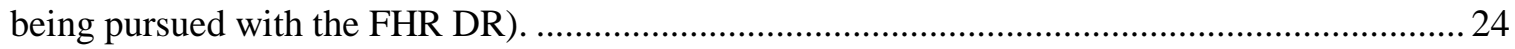

Fig. 19. Notional arrangement of the reactor vessel and thermal blanket within a reactor silo................. 25

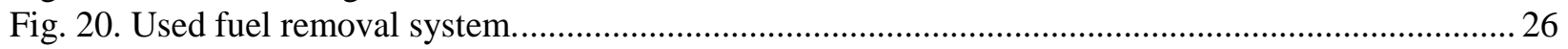

Fig. 21. Intermediate piping passing out of the reactor building (above) and into an adjacent building housing the intermediate transport system and power dissipation equipment

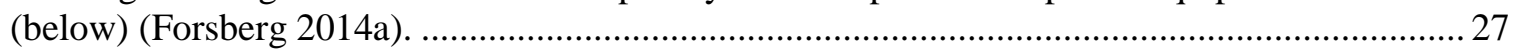

Fig. 22. FHR DR vessel showing DRACS heat exchangers (red) ........................................................ 28

\section{LIST OF TABLES}

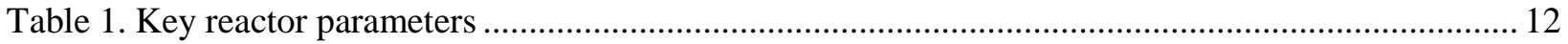

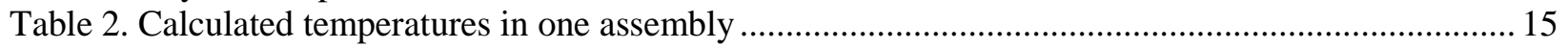

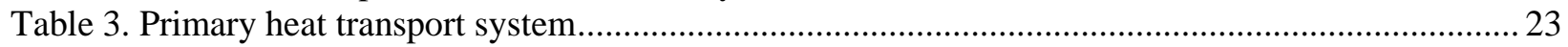

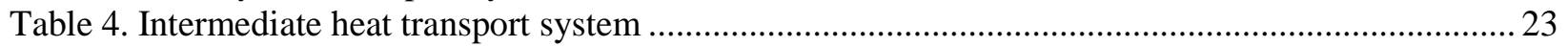





\section{ABBREVIATIONS AND ACRONYMS}

$\begin{array}{ll}\text { AGR } & \text { advanced gas reactor } \\ \text { AHTR } & \text { advanced high-temperature reactor } \\ \text { ART } & \text { Advanced Reactor Technology } \\ \text { B } 4 & \text { boron carbide } \\ \text { BOC } & \text { beginning-of-cycle } \\ \text { C-C } & \text { carbon-carbon } \\ \text { DOE } & \text { US Department of Energy } \\ \text { DR } & \text { demonstration reactor } \\ \text { DRACS } & \text { direct reactor auxiliary cooling system } \\ \text { EOC } & \text { end-of-cycle } \\ \text { FCM } & \text { fully ceramic micro-encapsulated } \\ \text { FHR } & \text { fluoride salt-cooled high-temperature reactor } \\ \text { FLiBe } & \text { 2 } 7 \text { LiF - BeF } 2 \\ \text { FLiNaK } & \text { 47 mol\% LiF, 11 mol\% NaF, and 42 mol\% KF } \\ \text { HTGR } & \text { high-temperature gas-cooled reactor } \\ \text { I\&C } & \text { instrumentation and control } \\ \text { ID } & \text { inner diameter } \\ \text { IET } & \text { integrated effects test } \\ \text { LOFF } & \text { loss of forced flow } \\ \text { LOOP } & \text { loss of offsite power } \\ \text { LWR } & \text { light water reactor } \\ \text { MHC } & \text { molybdenum-hafnium-carbide } \\ \text { MIT } & \text { Massachusetts Institute of Technology } \\ \text { NGNP } & \text { next generation nuclear plant } \\ \text { NHES } & \text { Nuclear Hybrid Energy System } \\ \text { PB-FHR } & \text { pebble bed FHR } \\ \text { PHTS } & \text { primary heat transport system } \\ \text { RD\&D } & \text { research, development, and demonstration } \\ \text { RVACS } & \text { reactor vessel auxiliary cooling system } \\ \text { SET } & \text { separate effects test } \\ \text { SiC } & \text { silicon carbide } \\ \text { SmAHTR } & \text { small modular AHTR } \\ \text { SMR } & \text { small modular reactor } \\ \text { TH } & \text { thermal hydraulic } \\ \text { TRISO } & \text { tristructural-isotropic } \\ \text { TRL } & \text { technology readiness level } \\ \text { UCB } & \text { University of California, Berkeley } \\ \text { UCO } & \text { uranium oxycarbide } \\ & \end{array}$





\section{ACKNOWLEDGEMENTS}

This report benefits greatly from the efforts of many individuals and institutions performing research on Fluoride Salt-Cooled High-Temperature Reactors. We would like to credit the two Integrated Research Projects funded by the US Department of Energy Office of Nuclear Energy led by the Massachusetts Institute of Technology (MIT) and Georgia Institute of Technology and to thank Dr. Charles Forsberg (MIT), Prof. Per Peterson (University of California, Berkeley), Dr. David Holcomb (Oak Ridge National Laboratory), Dr. Joshua Richard (Los Alamos National Laboratory), Dr. John Stempien (Idaho National Laboratory), Prof. Raluca Scarlat (University of Wisconsin), and Dr. Michael Laufer (University of California, Berkeley) specifically for their gracious sharing of information and helpful insights. 



\section{SUMMARY}

Development of the Fluoride Salt-Cooled High-Temperature Reactor (FHR) Demonstration Reactor (DR) is a necessary intermediate step to enable commercial FHR deployment through disruptive and rapid technology development and demonstration. The FHR DR will utilize known, mature technology to close remaining gaps to commercial viability. Lower risk technologies are included in the initial FHR DR design to ensure that the reactor can be built, licensed, and operated within an acceptable budget and schedule. These technologies include tristructural-isotropic (TRISO) particle fuel, replaceable core structural material, the use of that same material for the primary and intermediate loops, and tube-and-shell heat exchangers.

The FHR is a class of molten salt reactors that uses fluoride salts as low pressure coolants to produce hightemperature heat with high degrees of passive safety. The two main variants of molten salt reactors are solidfueled salt-cooled reactors and salt-fueled reactors. In recent years, Oak Ridge National Laboratory (ORNL), the University of California, Berkeley (UCB), and the Massachusetts Institute of Technology (MIT) (among others) have developed salt-cooled FHR concepts denoted Advanced High Temperature Reactors (AHTR). The AHTR leverages proven TRISO particle fuel technology and the beneficial aspects of salt coolants.

Several preconceptual and conceptual design efforts have been conducted on AHTR concepts, and the FHR DR is heavily influenced by them. Specific designs include the ORNL AHTR with 3400/1500 megawatts of thermal output (MWt) / megawatts of electric output (MWe) (Holcomb et al. 2011a), as well as a $125 \mathrm{MWt}$ small modular AHTR (SmAHTR) from ORNL (Greene et al. 2010). Other important examples are the Mk1 pebble bed FHR (PB-FHR) concept from UCB, the corresponding Mark 1 PB-FHR baseline commercial FHR platform, and an FHR test reactor design developed at MIT. The MIT FHR test reactor is based on a prismatic fuel platform and is directly relevant to the present FHR DR point design effort. These FHR concepts, some of which are shown in Fig. 1, are based on reasonable assumptions for a credible commercial prototype. The FHR also directly benefits from the operating experience of the Molten Salt Reactor Experiment (MSRE), as well as the detailed design efforts for a large molten salt reactor concept and its breeder variant, the Molten Salt Breeder Reactor.

The FHR DR reactor concept is shown in Fig. 2 and Fig. 3. Key features of the FHR DR concept are directly relevant and scalable to commercial applications. Examples include (1) the use of hexagonal fuel arrangements with TRISO fuel in a graphite matrix, (2) the ability to move and replace fuel structures within the core, and (3) active and passive Direct Reactor Auxiliary Cooling Systems (DRACS). Active safety systems accelerate licensing and deploying the FHR DR because adequate data do not exist to prove performance of passive salt-based heat removal safety systems for licensing purposes. Active heat exchangers have also been proposed for heat removal during maintenance outages for integral FHRs such as the SmAHTR. The FHR DR will use active systems to enable licensing and operation. The FHR DR will then demonstrate passive safety system operation and generate the data needed for licensing and deployment of passively-safe commercial FHRs.

Important capabilities that will be demonstrated by building and operating the FHR DR include core design methodologies; fabrication and operation of high temperature reactors; salt procurement, handling, maintenance, and ultimate disposal; salt chemistry control to maximize vessel life; tritium management; heat exchanger performance; pump performance; and reactivity control. The FHR DR is considered part of a broader set of FHR technology development and demonstration efforts, some of which are already underway. Nonreactor test efforts (e.g., heated salt loops or loops using simulant fluids) can demonstrate many technologies necessary for commercial deployment of FHRs. The FHR DR, however, fulfills a crucial role in FHR technology development by advancing the technological maturity and readiness level of the system as a whole. 
This report provides an update on the development of the FHR DR. At this writing, the core neutronics and thermal hydraulics have been developed and analyzed. The mechanical design details are still under development and are described to their current level of fidelity. The construction timeline and cost estimation are in the early stages of development and are not described in this report. However, it is anticipated that the FHR DR can be operational within 10 years because of the use of low-risk, near-term technology options.

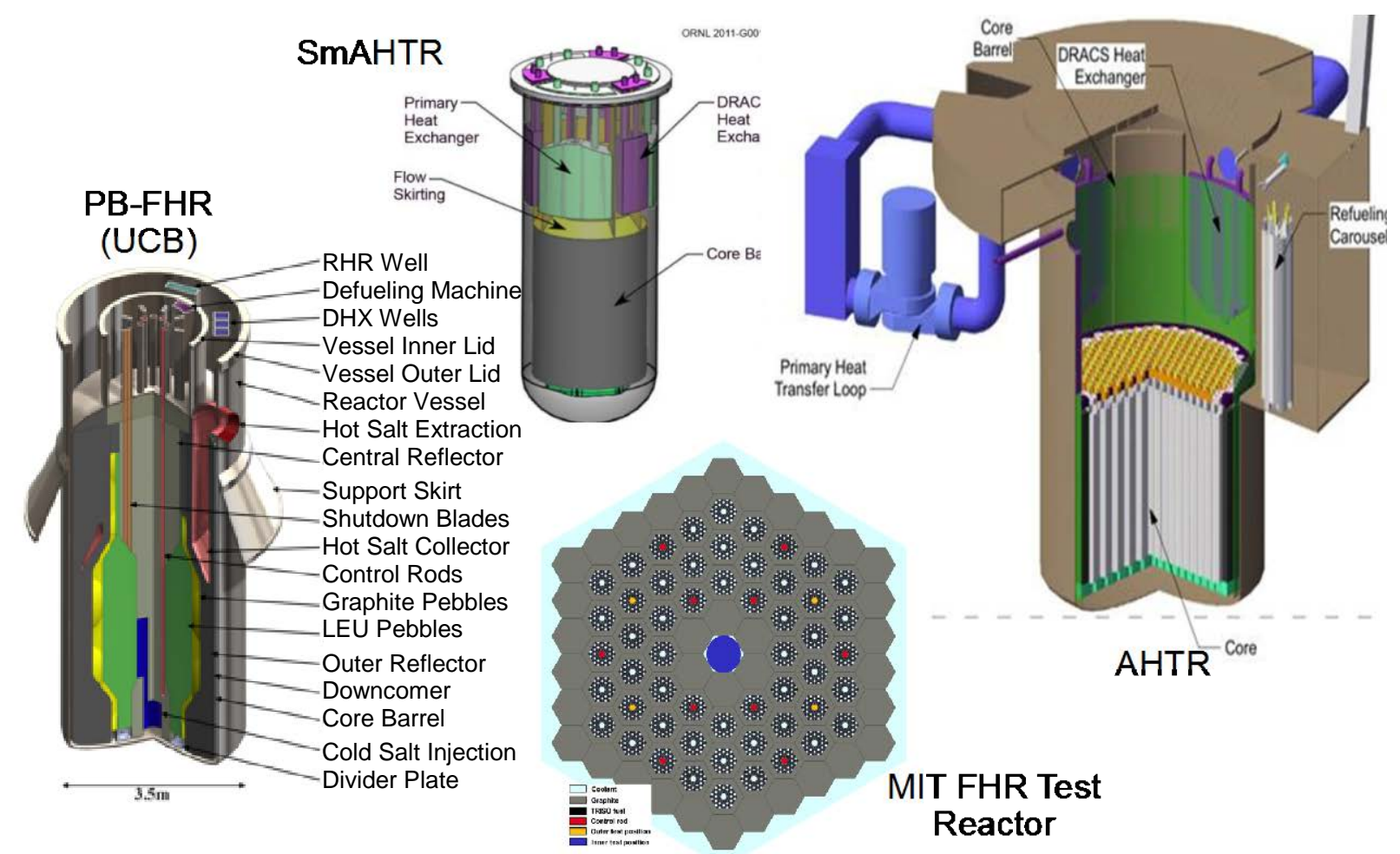

Fig. 1. FHR DR demonstrates features of several promising FHR concepts. 


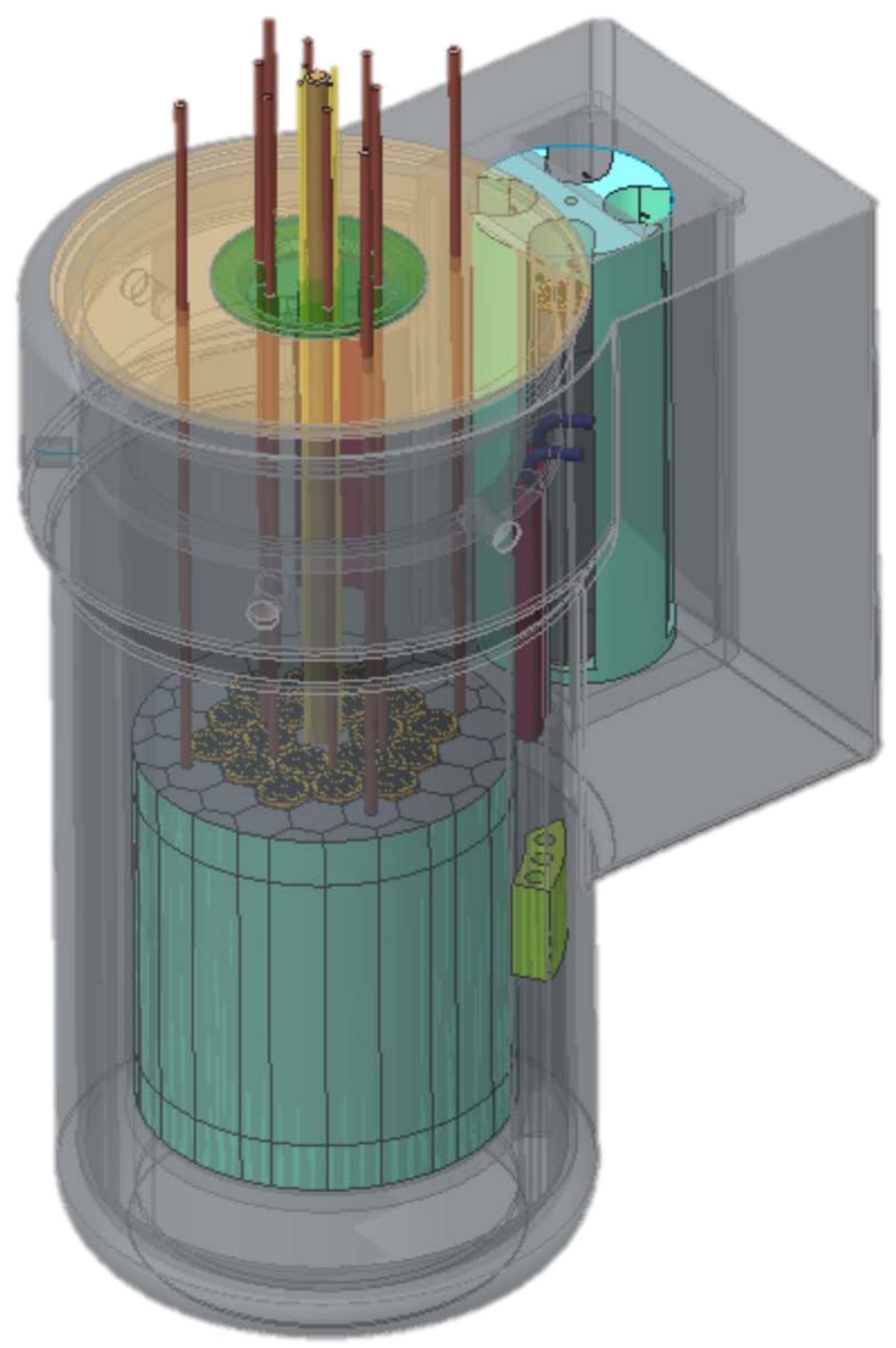

Fig. 2. FHR DR vessel and core concept. 


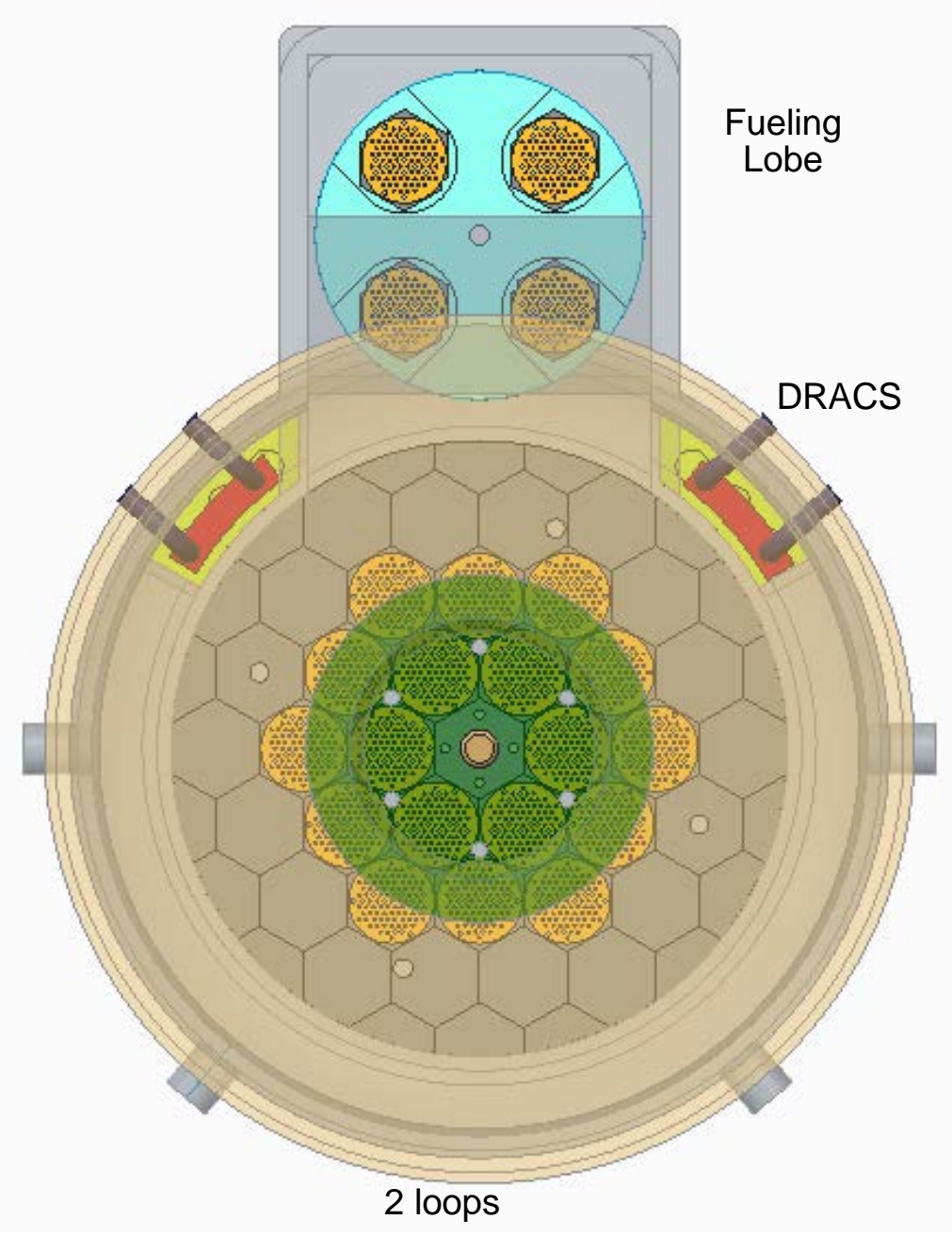

Fig. 3. Top view of the FHR DR concept.

The FHR DR is a 100 MWt salt-cooled reactor that uses TRISO particle fuel within prismatic graphite blocks. FLiBe $\left(2{ }^{7} \mathrm{LiF}-\mathrm{BeF}_{2}\right)$ is the primary coolant. However, the FHR DR is capable of testing other candidate salt coolants. The FHR DR is similar in many respects to the ORNL AHTR and SmAHTR concepts. The core resides in a pool of primary coolant salt within a cylindrical vessel of alloy $800 \mathrm{H}$ lined with alloy N. Primary coolant flows into the vessel above the core, flows downward along the vessel wall into a lower plenum, and then it flows upward through the core. A core barrel separates the downcomer and core regions. The vessel is housed in a reactor silo and is covered with a removable top hatch. The primary heat transport system (PHTS) is a two-loop system with heat exchange to independent intermediate loops each carrying $~ 50 \mathrm{MWt}$ to a common salt containment vessel. The baseline design of the FHR DR is coupled to an open-air Brayton power conversion system, which is also proposed for the Mk 1 pebble bed FHR concept. 


\section{OBJECTIVES AND MOTIVATION FOR CONCEPT SELECTION}

The FHR DR provides an environment to validate key features of FHRs before commercial deployment. It is a flexible facility where solutions can be tested to bridge remaining technology gaps. The FHR DR is designed to be an affordable, near-term system that can plausibly be operational within a decade. To meet that goal, lower risk technology identified from previous experimental and design efforts are incorporated into the design. However, the flexible facility also allows inclusion, demonstration, and qualification of other technologies being pursued for commercial development efforts.

Technology gaps for FHRs include demonstration of a fuel form for a viable commercial plant (including the ability to efficiently install and remove a core), in-core structural material performance, and passive safety performance. Additional operational needs applicable to salt reactors include salt procurement, chemistry control, and tritium management of lithium- and beryllium-containing salts. More routine needs include demonstration of reliable pump and heat exchanger performance at temperatures of interest using relevant salt coolants. In addition, demonstration of control rod drive mechanisms will be an important aspect of the FHR DR.

The operating paradigm for the FHR DR will resemble Shippingport, the historic light water reactor (LWR) test bed that demonstrated three completely different core designs within the same vessel. Similar flexibility in the FHR DR allows for testing of different fuel forms and cores as they become available. Multiple fuel forms were evaluated and deemed acceptable for neutronics and thermal hydraulics within the FHR DR core. Based on an assessment of technology readiness, the baseline fuel form selected for the FHR DR was TRISO fuel compacts within a prismatic graphite block. This was previously demonstrated in high-temperature gascooled reactors.

The FHR DR vessel shares flow characteristics with other FHR concepts, including a ringed distribution manifold to direct the cooler inlet primary coolant downward over the vessel's inner surface to maintain the vessel at minimum coolant temperatures. A lower core support structure incorporates flow distribution plates to regulate flow from the lower vessel plenum upward through the core. Two isolated sections within the downcomer region on the inner vessel wall house independent heat exchangers to remove heat directly from the primary salt within the vessel in the event of a loss of flow accident.

The FHR DR combines a pool reactor and a distributed looped system in which pumps and heat exchangers are separate and displaced from the reactor vessel and core. The distributed layout provides physically isolated locations for distinct technology demonstration activities and makes it easier to remove and replace tested hardware with improved technology as it becomes available. Heat exchangers transfer heat from the two primary loops to two intermediate heat transfer loops. Thus the heat transport system consists of two primary pumps, two primary-to-intermediate salt-to-salt heat exchangers, and two intermediate salt pumps. The salt from both intermediate loops is directed to a single insulated container.

The FHR DR baseline design produces electricity but it can also demonstrate the ability of an FHR to supply low-pressure, high-temperature process heat directly to a chemical process. Heat from the intermediate salt can be shared among a number of uses depending on the desired configuration of the plant. This approach is based on concepts being developed in the Nuclear Hybrid Energy System (NHES) project as part of the US Department of Energy (DOE) Advanced Reactor Technology (ART) program (Bragg-Sitton, 2014). In this approach, heat is directed according to current environmental or economic conditions. Fig. 4 shows an example of the integration of a nuclear reactor as a heat source in a tightly coupled hybrid energy system, which includes renewable generation and a dedicated industrial customer. Alternatively, the entire thermal production of the FHR DR can be rejected to the environment through a cooling tower if desired. 


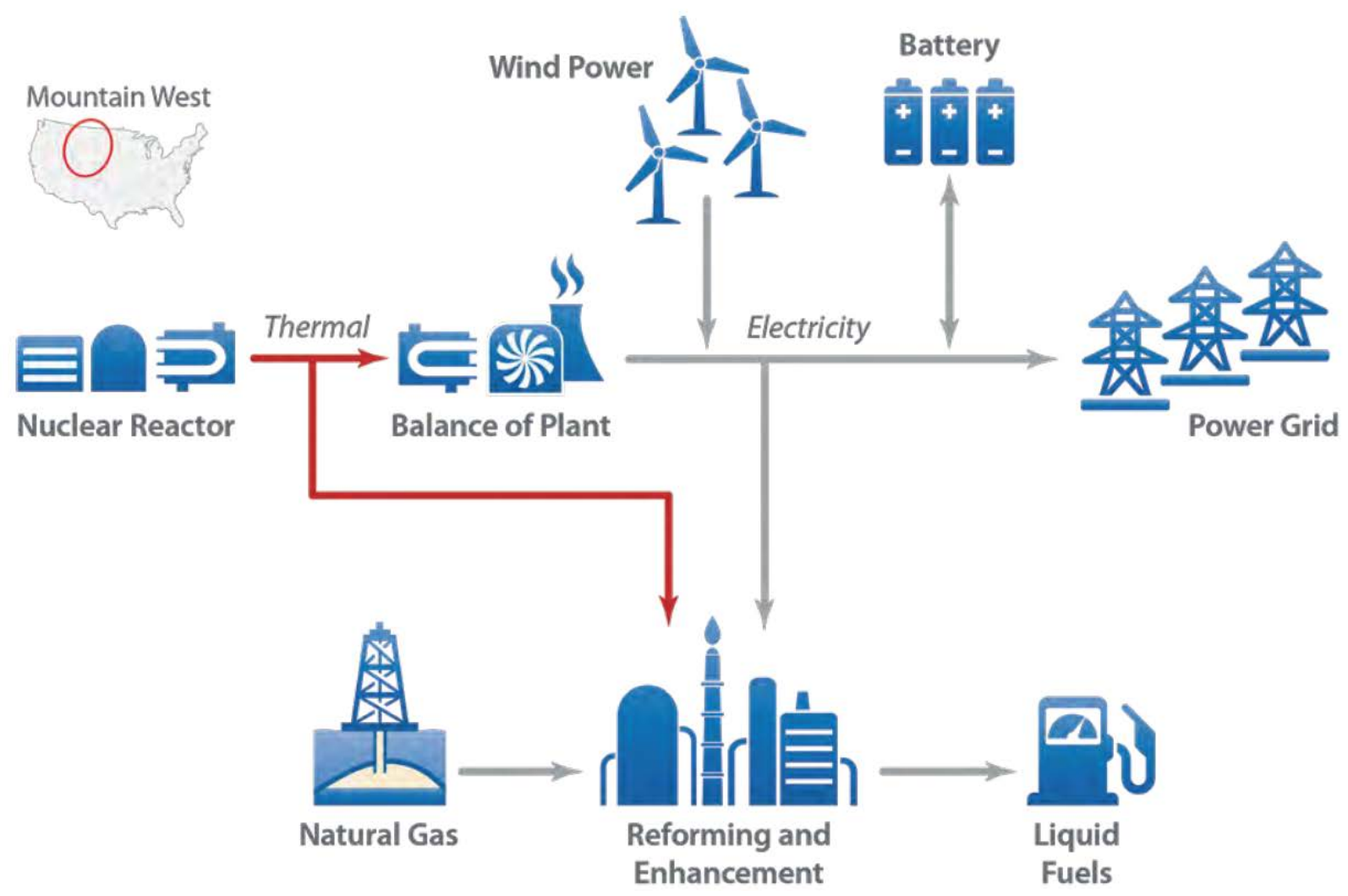

Fig. 4. Nuclear renewable hybrid energy system (Bragg-Sitton, 2014).

The FHR DR thermal power level is $100 \mathrm{MWt}$. This is representative of the power of DOE's currently operating reactors, the HFIR at ORNL (85 MWt) and the ATR at INL (250 MWt). and is similar to the power level of the SmAHTR design (125 MWt). This power level is sufficient for fuel irradiation and produces operational characteristics that are relevant to FHR commercial systems. It also represents power levels being considered for several small modular reactor (SMR) concepts. The material combinations in the FHR DR's primary system are those currently considered to be most suitable for a near-term demonstration. They were chosen based on their increased maturity, availability, and for licensing considerations. Materials with less resistance to irradiation damage or corrosion can be considered for a demonstration reactor due to the planned shorter operational life. Using available materials allows the FHR DR to be operational sooner, which allows it to be available to test any number of commercially attractive materials earlier.

\subsection{TECHNOLOGY ASSESSMENT}

The FHR Technology Development and Demonstration Roadmap (Holcomb et al. 2013) identified several "remaining technology challenges and the research, development, and demonstration $(R D \& D)$ needed to address the challenges.” While some key FHR technologies could largely be developed and demonstrated using nonreactor experiments (e.g., lithium enrichment, fuel pebble handling for PB-FHR, and some salt handling issues), many technology development and demonstration gaps can only be addressed by successfully designing, licensing, building, and operating an FHR. These include design performance prediction, infrastructure and regulatory maturation, and development and demonstration of systems and components at capacities that can be confidently scaled to commercial deployment. Infrastructure and regulatory maturation goals include (1) developing and demonstrating a licensing path specifically for FHRs 
and by extension for advanced (non-water-cooled) reactors in general, (2) providing validation data for computational modeling and simulation capabilities in areas including reactor analysis, safety performance and salt chemistry modeling, (3) demonstrating key fabrication techniques for FHR reactor components, and (4) developing a supply chain for FHR-specific components and materials, including fuels and salts. System and component technology goals include (1) developing and demonstrating FHR-specific instrumentation and control (I\&C) systems (e.g., optically based instrumentation), (2) fuel demonstration and qualification, and (3) using refueling technologies needed to support commercial FHR operation.

Other FHR technology priorities may be partially addressed without building a demonstration reactor, but building and operating an FHR DR would result in important demonstration benefits. These include tritium control, TRISO particle fuel qualification in FHR specific service conditions, salt chemistry control (e.g., redox control), salt cleanup (e.g., cleaning fission products and radiolytic compounds from the primary coolant), structural alloy development and qualification, continuous fiber composite development and qualification, and component development and qualification. Each of these technology needs could be developed to some degree without an FHR DR using facilities for separate effects tests (SETs) and integrated effects tests (IETs), but an operating FHR DR would enable focused and rapid technological maturation, prototypic deployment, and credible demonstration.

TRISO fuel forms are the most promising option for FHRs in the near term, and they are the first fuel form to be demonstrated in the FHR DR. Several recent salt-cooled reactor concepts also rely on TRISO fuel particles in various graphite fuel forms. The UCB Mk1 concept uses fuel pebbles in a packed bed, the SmAHTR concept assumes TRISO particles in fuel planks, and the MIT FHR test reactor design uses prismatic fuel blocks similar to high-temperature gas-cooled reactor (HTGR) fuel. Although they were generally developed for lower operating power densities and higher operating temperatures, some TRISO fuel qualification irradiation conditions appear to be relevant to the anticipated conditions of the FHR DR TRISO fuel.

Other fuel forms that may be considered for use in FHRs include the advanced fuel forms being considered for LWR enhanced accident tolerance in the DOE Office of Nuclear Energy Advanced Fuels Campaign. Advanced nitride and silicide composite fuel forms $\left(\mathrm{U}_{3} \mathrm{Si}_{2}, \mathrm{UN}-\mathrm{U}_{3} \mathrm{Si}_{5}\right.$, etc.) or fully ceramic microencapsulated (FCM) fuel with UN-based fuel kernels could be coupled with SiC-SiC cladding or molybdenum-based cladding in a commercial FHR. These advanced fuel forms could potentially enhance natural uranium resource utilization, reduce fuel cycle costs, and enable operation with enrichment levels less than $5 \%$. The ability to test and demonstrate these new fuel concepts in the FHR DR is a key feature of its design.

FHR concepts may benefit from advanced nonmetal materials that form some of the plant's lifetime structural components, but these materials are not yet qualified for use in reactors. The FHR DR approach to accommodate near-term deployment is borrowed from the UCB Mk1 concept of making critical core structures removable and replaceable along with used fuel. The reactor vessel is designed with a bolted core structure interface to allow new and potentially different core structures to be operated within the same facility.

FHR technology demonstration needs include the ability to procure, handle, and maintain the required salts; install the necessary heat exchange and pumping equipment; and maintain components and systems after operation. These objectives would be accomplished using remote maintenance equipment and automated processes to the extent possible. Tritium management is also a key challenge with FHRs, and multiple solutions to this issue will be tested in the FHR DR facility. Tritium management approaches under consideration include gettering with out-of-core packed spherical beds, sweep gas in a double-walled heat exchanger, and diffusion barriers. Combinations of different technologies may ultimately be required. 


\section{POINT DESIGN DESCRIPTION}

\subsection{REACTOR FUEL FORM AND CONFIGURATION}

The FHR DR uses prismatic block-type fuel with integral fuel compacts and coolant channels as its base fuel form. The fuel is a typical next generation nuclear plant (NGNP) particle geometry with $15.5 \% \mathrm{UC}_{0.5} \mathrm{O}_{1.5}$ TRISO kernels with packing fractions of 0.35 within compacts. Selection of prismatic block-type fuel was motivated by the manufacturability of the prismatic fuel for HTGRs. The recent experience in the Advanced Gas Reactor (AGR) fuel irradiation program is another reason for this selection. Prismatic block fuel provides significant flexibility in enrichment zoning, fuel-coolant-moderator ratio, coolant distribution, and other core design parameters. The cycle length of the FHR DR core is estimated at 12-18 months, with the following characteristics:

- prismatic block construction with an assembly pitch of $46 \mathrm{~cm}$,

- 18 fueled positions,

- 180 fuel compacts and 109 coolant channels per fueled position,

- core height of $350 \mathrm{~cm}$ with a fueled height of $261 \mathrm{~cm}$,

- core diameter of $324 \mathrm{~cm}$ with a fueled diameter of $231 \mathrm{~cm}$, and

- $100 \mathrm{MW}$ thermal power.

The completed core consists of 18 fueled hexagonal positions surrounded by 18 full-sized unfueled positions, as shown in Fig. 5. A full-sized central hexagonal position is reserved for irradiation and instrumentation services. Partial sections fill in the outer edges to complete the circle, which limits bypass flow between the core and the structure that restrains the core and forms the downcomer region within the vessel.

The baseline prismatic block fuel has the same hexagonal flat-to-flat distance as the reference plank fuel assembly for SmAHTR and AHTR concepts. Therefore, the FHR DR core could later be exchanged for a similar plank-fueled core. Other proposed FHR fuel forms include uranium oxide, carbide, or nitride fuel pellets with an advanced cladding (SiC-SiC or molybdenum-based), fuel particles in cylindrical fuel compacts within prismatic graphite blocks, stringer fuel designs where particle fuel compacts are directly cooled by salt, fuel particles in graphite pebbles, and fuel particles in ceramic planks. AREVA NP Inc. (2007) previously investigated the potential for oxide pellet fuel forms in various fuel cycle missions within FHRs (e.g. burning of mixed-oxide fuel). The FHR DR has the capability to test any of these fuel forms prototypically (full height/power density) within the central unfueled hexagonal position. These capabilities include operation of lead test assemblies with instrumentation. The pebble fuel form would be tested within a fixed pebble bed in the central location, but pebble handling would be demonstrated in other facilities.

In addition to the central test location, fully instrumented irradiation locations in nonfuel blocks near the perimeter of the core allow for material specimen irradiations within instrumented and temperature controlled capsule assemblies.

For shutdown margin and additional reactivity control, the FHR DR uses molybdenum-hafnium-carbide (MHC) control rods. Commercially available MHC features high density, strength, and corrosion resistance which are the primary reasons it was selected as the baseline reactivity control material. Boron carbide $\left(\mathrm{B}_{4} \mathrm{C}\right)$ is also under consideration for the final design, as it is a strong neutron absorber also compatible with high temperatures. However, the low density of $\mathrm{B}_{4} \mathrm{C}$ requires it to be weighted with an additional dense material (e.g., tungsten carbide). Control rods are inserted into the core using mechanisms mounted to a removable central top plug on the vessel's top hatch. The rods are detachable from the control drive mechanisms and sink into the primary coolant when detached. 
Access to perimeter instrumentation and irradiation locations is through openings on the outer ring of the vessel's top hatch. The instrumentation equipment is contained in cylindrical primary boundary containment housings that extend from the top hatch to the bottom of the reactor core. They can be removed and stored to facilitate core shuffling and refueling. Fig. 5 shows the location of control rods (red) and representative locations for instrumentation and irradiation holes (blue) within the core. The numbers and locations of the instrumentation and irradiation positions are selectable and reconfigurable.

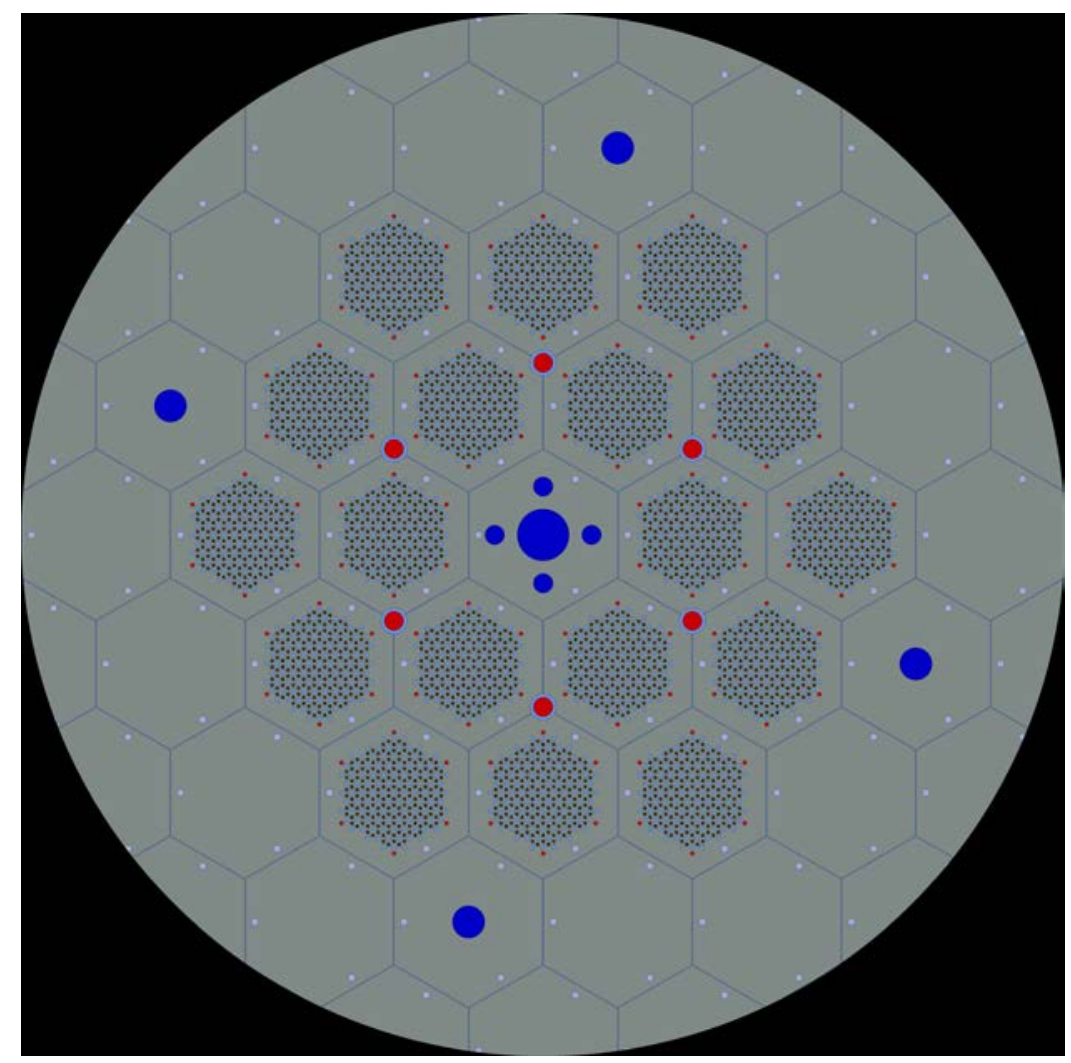

Fig. 5. Radial core layout of the neutronic model.

Three blocks — an upper unfueled section, a fueled central section, and a lower unfueled section-are structurally connected using tie rods to form a single hexagonal stack that spans the height of the core. Each block assembly is positioned by a lower core support plate attached to an internal support flange within the vessel. Fuel block assemblies are outfitted with lifting and locating hardware to allow for placement on the lower core support plate and for positioning and stabilization within the core. An orifice plate (Fig. 6) adds weight to the bottom of each block assembly to ensure that the assembly sinks. The plates intersect with the lower core support structure in a self-aligning manner and the tie rods allow the block to lock into the support structure. The plates regulate flow within specific coolant channels.

Rotatable, spring-loaded rods with cleats at the base pass through fuel blocks and are extended below the lower core structure plate to engage and lock block assemblies into position. Fuel block assemblies are also constrained by an upper plate. The upper plates of each block move independently to accommodate unique thermal expansion and/or dimensional changes experienced by individual blocks within the core. 


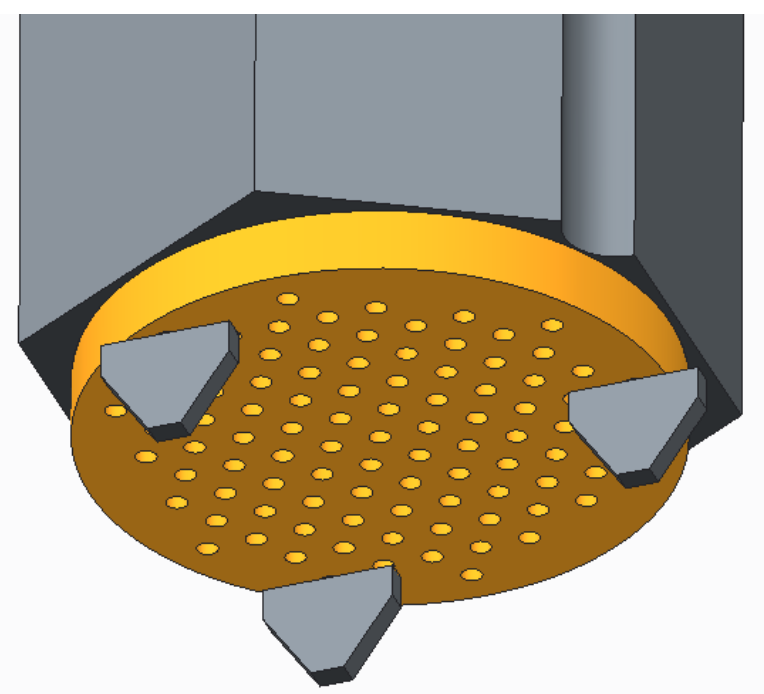

Fig. 6. View of a lower support plate of a fuel block assembly.

To control excess reactivity at the beginning of a cycle, each fueled assembly includes six burnable absorber rods located on the corners of the fuel region. These rods also reduce temperatures along the edges of the fueled regions, where the ratio of cooling to fuel channels is reduced. Absorber rods are composed of graphite with small weight fractions $(<2 \%)$ of natural $\mathrm{B}_{4} \mathrm{C}$ as a neutron absorber material similar to those used in HTGRs. The distribution of coolant and fuel channels within a hexagonal block is shown in Fig. 7. The current best estimate of the peak fuel temperature under worst-case conditions (within the graphite matrix as opposed to within a kernel) is $\sim 1200^{\circ} \mathrm{C}$.

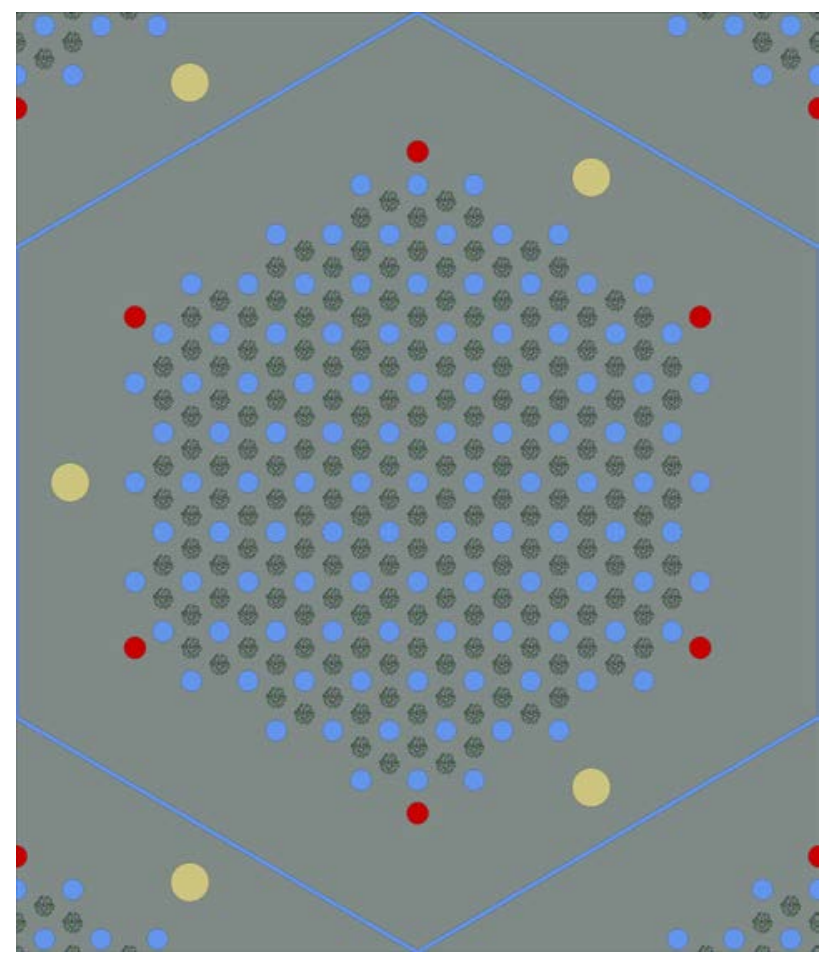

Fig. 7. Distribution of coolant and fueled channels within a FHR DR prismatic block. 


\subsection{REACTOR PHYSICS OF AN EXAMPLE CORE CONFIGURATION}

A variety of previous FHR concepts have featured acceptable core design parameters (Greene et al. 2010; Holcomb et al. 2011a; Holcomb et al. 2011b; Varma et al. 2012; Andreades et al. 2014; Forsberg et al. 2014a; Forsberg et al. 2014b). The current FHR DR core design effort is intended to ensure a workable system with sufficient detail to provide data for the program evaluation criteria and metrics. The current configuration is not considered the final point design, but it is an acceptable baseline core arrangement for further FHR DR development. Many core arrangements are possible, and flexibility in core configuration is a key feature of the concept. The current configuration is a single-batch fuel management scheme, but the planned approach for the equilibrium cycle operation of the FHR DR may be a multiple batch scheme. In comparison to the single-batch case the application of a multiple batch scheme decreases cycle length, but increases fuel residence time and discharge burn-up so that the operation may be more representative of commercial application.

The reactivity coefficients of the FHR DR are a key inherent safety feature of the reactor system. The fuel temperature coefficient and moderator temperature coefficient are both negative. The void coefficient is negative or negligible throughout the cycle. Present analysis indicates that the reactor could exhibit acceptable shutdown margin with either $\mathrm{MHC}$ or $\mathrm{B}_{4} \mathrm{C}$ control materials. It is significant to note that the FHR DR is a low-pressure system, and FLiBe boils at approximately $1430^{\circ} \mathrm{C}$. Therefore, a credible pathway to complete voiding is highly unlikely. The single-batch core $\mathrm{k}_{\mathrm{eff}}$ and the reactivity worth of complete voiding of the core are shown in Fig. 8 for an example configuration with 15.5\% enriched uranium oxycarbide (UCO) kernels and a 0.35 packing fraction.

The current core configuration assumes nickel-plated alloy $800 \mathrm{H}$ tie rods for fuel element structural materials. Alloy $800 \mathrm{H}$ is a near-term option that features excellent high temperature strength, but it has relatively high parasitic neutron absorption due to nickel and iron content. If C-C composites or SiC structural tie rods are possible, significantly longer single-batch cycle lengths are achievable. The peak fast neutron fluence $(>0.18 \mathrm{MeV})$ expected in the TRISO fuel kernels is $3.5 \times 10^{21} \mathrm{n} / \mathrm{cm}^{2}$. The maximum thermal flux achievable in the central thimble is on the order of $3 \times 10^{14} \mathrm{n} / \mathrm{cm}^{2}$-s, although this varies with fuel packing fraction and enrichment, core loading, and fuel assembly tie rod material.

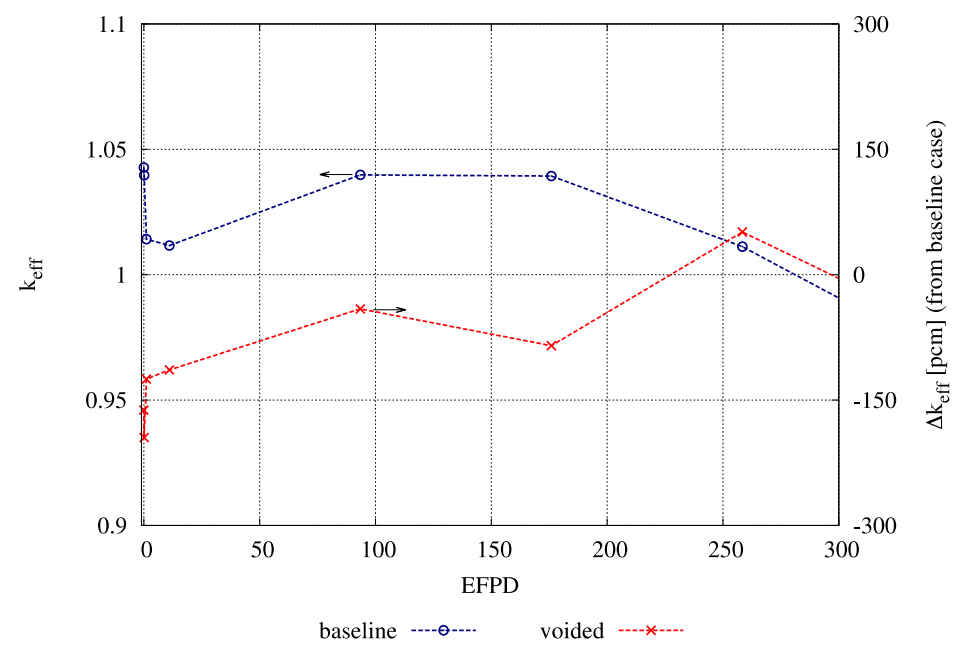

Fig. 8. Single-batch core $k_{\text {eff }}$ and complete void worth for an example core configuration.

Thermal flux and power distribution contour plots at the central midplane of the core are shown in Fig. 9. This example core configuration has been optimized for reactivity control using burnable poison. The burnable poisons used in this example configuration are based on the absorber design used in the Fort St. 
Vrain gas-cooled reactor. There are two types of flux depressions seen in Fig. 9: those resulting from the burnable absorber and those caused by the alloy $800 \mathrm{H}$ structural tie rods. Burnout of the burnable absorber from the beginning-of-cycle (BOC) to end-of-cycle (EOC) can be observed from the two plots.

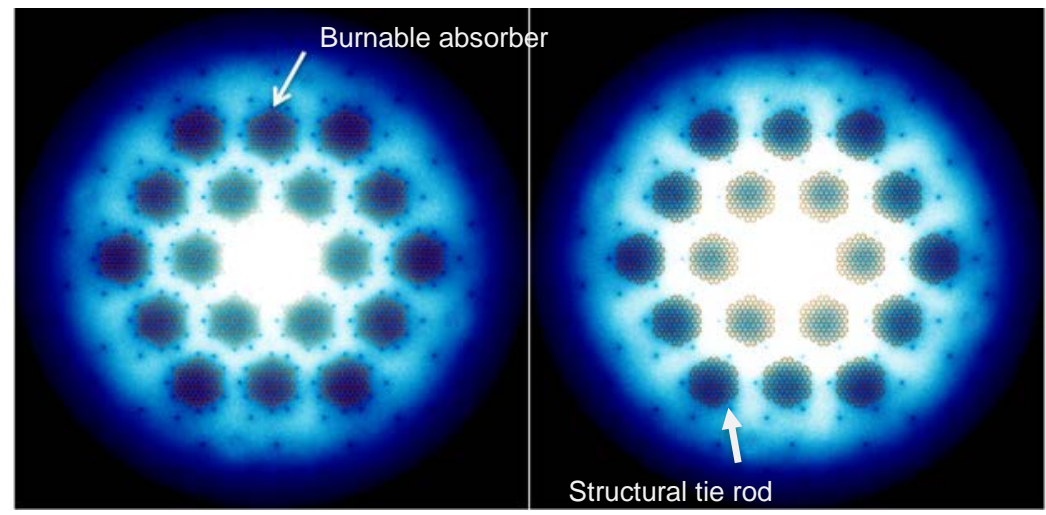

Fig. 9. Thermal neutron flux contours (blue shades) in the FHR DR at BOC (left) and EOC (right).

Key reactor design parameters of the current FHR DR configuration are shown in Table 1.

Table 1. Key reactor parameters

\begin{tabular}{|c|c|c|}
\hline Reactor thermal power & MWt & 100 \\
\hline $\begin{array}{l}\text { Targeted net thermal efficiency of derived } \\
\text { commercial application }\end{array}$ & $\%$ & $42-45$ \\
\hline Primary coolant & & $2^{7} \mathrm{LiF}-\mathrm{BeF}_{2}$ \\
\hline Lithium-7 enrichment level (initial) & $\%$ & 99.995 \\
\hline Fuel type & & $\mathrm{UC}_{0.5} \mathrm{O}_{1.5}$ coated particle \\
\hline Fuel packing & $\%$ & $30-40$ \\
\hline${ }^{235} \mathrm{U}$ enrichment level & $\%$ & 15.5 (baseline) \\
\hline Reflector material & & Graphite \\
\hline Reactor vessel internals material & & Alloy $800 \mathrm{H}$ lined w/alloy $\mathrm{N}$ \\
\hline Core structural material & & C-C composite \\
\hline Control blade material & & MHC alloy \\
\hline Primary coolant flow rate & $\mathrm{kg} / \mathrm{s}$ & $\sim 1000$ \\
\hline Number of primary loops & & 2 \\
\hline Refueling interval & Months & $12-18$ \\
\hline Fuel format & & $\begin{array}{l}\text { Prismatic block with coolant channels } \\
\text { and fuel compacts }\end{array}$ \\
\hline Mixed mean core outlet temperature & ${ }^{\circ} \mathrm{C}$ & 700 \\
\hline Core inlet temperature & ${ }^{\circ} \mathrm{C}$ & 660 \\
\hline Number of fuel assemblies & & $\begin{array}{l}18 \text { fueled (baseline core, configuration } \\
\text { is flexible) }\end{array}$ \\
\hline Vessel material & & Alloy $800 \mathrm{H}$ lined w/Alloy $\mathrm{N}$ \\
\hline Core fueled height & $\mathrm{m}$ & 2.61 \\
\hline Core pressure drop for normal operation & atm & 0.6 \\
\hline
\end{tabular}

Several options are being considered for a diverse secondary shutdown system as required in the generic design criteria. A summary of the options under consideration from Greene et al. (2010) include (1) redundant and diverse control rod systems, (2) an absorber injection system, (3) absorber balls or pellets, and 
(4) expansion modules. The baseline configuration for the FHR DR is expected to be an absorber injection system, but various secondary shutdown systems could be demonstrated in the FHR DR.

\subsection{THERMAL-HYDRAULIC CALCULATIONS}

Two codes were used to perform FHR DR thermal-hydraulic (TH) design calculations: COMSOL (COMSOL Code 2015) and RELAP5-3D (RELAP5-5D Code Development Team 2014). The COMSOL code was used to calculate fuel and graphite temperatures in one assembly, and the RELAP5-3D code was used to perform overall system calculations. Different designs were investigated, and several iterations between the neutronics and the TH designs occurred until the current core design was selected.

\section{COMSOL Calculations}

The COMSOL model for one fuel block assembly of the proposed core is shown in Fig. 10. This model is for an average assembly, using average values for (1) the volumetric heat generation rate in the fuel compacts $\left(96.7 \times 10^{6} \mathrm{~W} / \mathrm{m}^{3}\right),(2)$ the coolant temperature $\left(680^{\circ} \mathrm{C}\right)$, which is the average of the inlet $\left(660^{\circ} \mathrm{C}\right)$ and the outlet $\left(700^{\circ} \mathrm{C}\right)$ temperatures, and $(3)$ the heat transfer coefficient in the coolant channels $\left(\sim 8,300 \mathrm{~W} / \mathrm{m}^{2} /{ }^{\circ} \mathrm{C}\right)$. No heat is assumed to be generated in the graphite; all the heat is assumed to be generated in the fuel compacts. This is a conservative modeling approach to predict high fuel temperatures. All the fuel compacts in the assembly are assumed to have the same heat generation rate with no variations. The graphite block sides are assumed to be adiabatic and any bypass flow is ignored. The model has 109 coolant holes and 180 fuel compacts. The calculated compact-averaged fuel temperatures vary between $936^{\circ} \mathrm{C}$ at the edges and $973^{\circ} \mathrm{C}$ at the center of the graphite fuel block-a temperature difference of $37^{\circ} \mathrm{C}$-and an average fuel temperature of $954^{\circ} \mathrm{C}$. The calculated graphite temperature at the edges is $714^{\circ} \mathrm{C}$. Fig. 10, Fig. 11, and Fig. 12 show the calculated temperatures in the fuel block.

\section{Surface: Temperature (degc)}

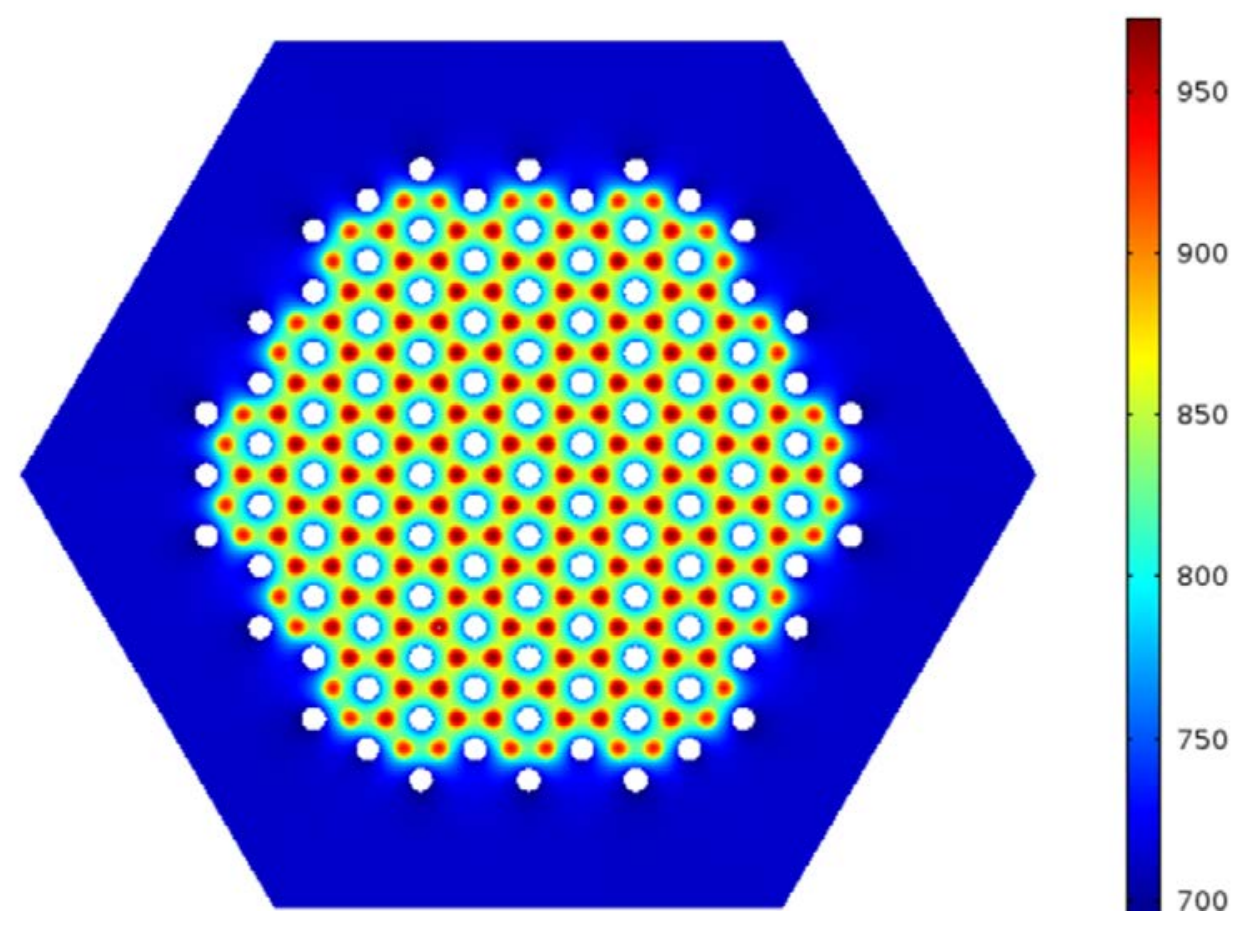

Fig. 10. COMSOL model and calculated temperatures in an average fuel block. 


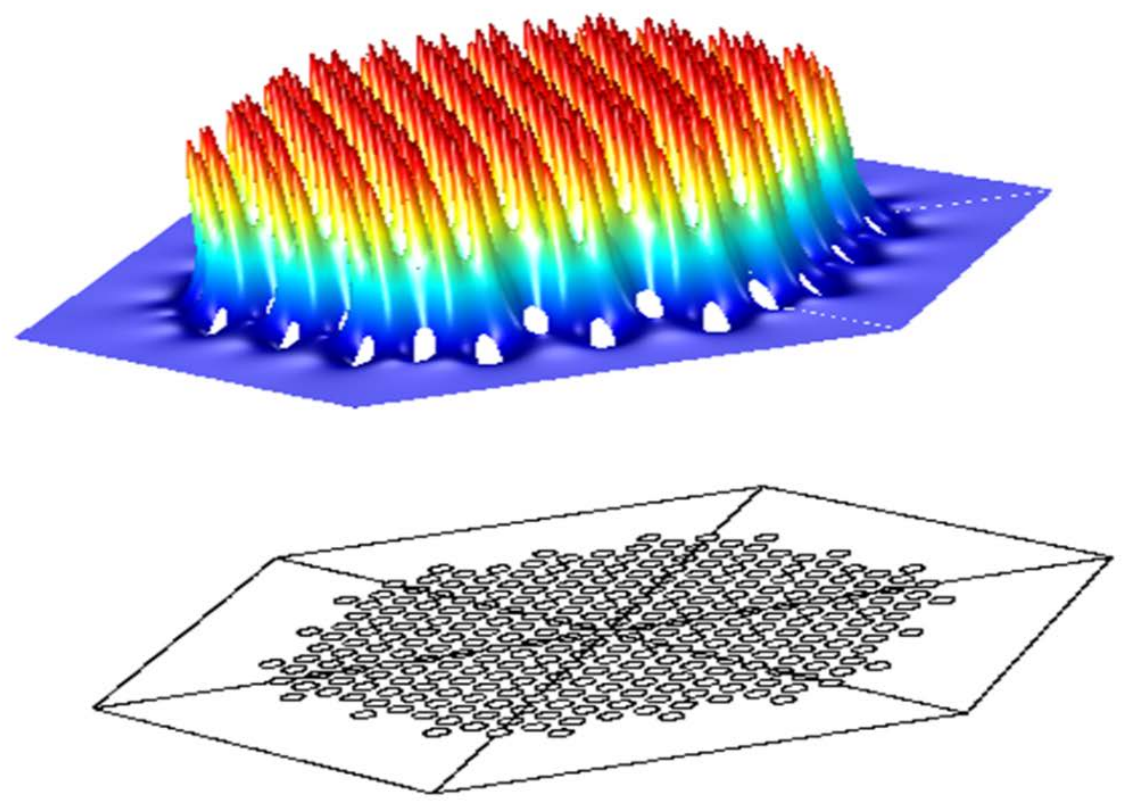

Fig. 11. Calculated temperatures in an average fuel block. Surface: Temperature (degc)

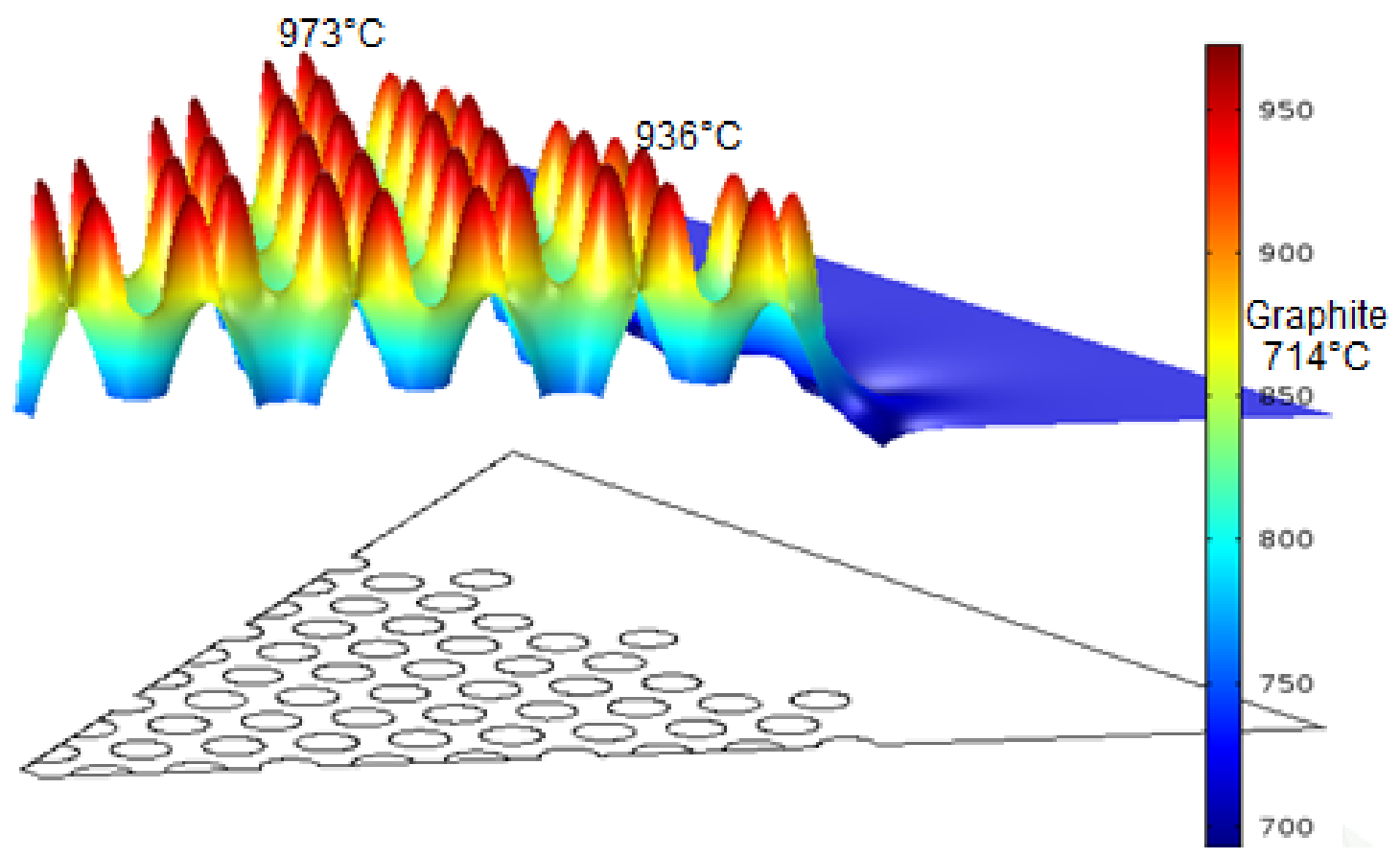

Fig. 12. Calculated temperatures in the fuel and in the graphite $-1 / 6$ section. 
Calculations for the maximum possible fuel temperatures were also completed using very conservative input values. For this case, the heat generation rate in the fuel was multiplied by the radial and axial peaking factors $(1.33 \times 1.28=1.7024$ or $70.2 \%$ higher than the average value); the maximum coolant temperature was used $\left(700^{\circ} \mathrm{C}\right.$ at the exit), together with a low heat transfer coefficient $\left(\sim 8000 \mathrm{~W} / \mathrm{m}^{2} /{ }^{\circ} \mathrm{C}\right)$. No heat was assumed to be generated in the graphite. The maximum calculated temperature is $1,195^{\circ} \mathrm{C}$, and the minimum calculated temperature is $1,133^{\circ} \mathrm{C}$, resulting in a calculated temperature difference of $62^{\circ} \mathrm{C}$. Calculated temperatures for this case and for the average case are summarized in Table 2.

Table 2. Calculated temperatures $\left({ }^{\circ} \mathrm{C}\right)$ in one assembly

\begin{tabular}{lcccccccc}
\hline CASE & $\begin{array}{c}\text { Volumetric heat } \\
\text { generation rate } \\
\text { in fuel compacts } \\
\left(\mathbf{W} / \mathbf{m}^{\mathbf{3}} \times \mathbf{1 0}^{\mathbf{6}} \mathbf{)}\right.\end{array}$ & Coolant & Graphite & $\begin{array}{c}\text { Fuel } \\
\text { Maximum }\end{array}$ & $\begin{array}{c}\text { Fuel } \\
\text { Minimum }\end{array}$ & $\boldsymbol{\Delta}$ & $\begin{array}{c}\text { Fuel } \\
\text { Average }\end{array}$ \\
\hline Average & 96.7 & 680 & 714 & 973 & 936 & 37 & 954 \\
Maximum & 164.6 & 700 & 755 & 1195 & 1133 & 62 & --- \\
\hline
\end{tabular}

The COMSOL calculations show that the fuel temperature differences in one assembly are moderate $\left(<62^{\circ} \mathrm{C}\right.$ maximum and only $37^{\circ} \mathrm{C}$ for an average assembly) and that the maximum calculated fuel temperature is under $1,200^{\circ} \mathrm{C}$ using conservative input values that cannot occur simultaneously. Actual maximum fuel temperatures will be lower than this value under normal operating conditions.

\section{RELAP5-3D Calculations}

Several RELAP5-3D models were prepared to investigate different components of the system. Some models were prepared for the vessel only including the inlet and outlet lines and the pumps. Other models were prepared for the heat exchangers, and another set of models was prepared for the complete system. Fig. 13 shows the nodalization of the complete system with the two primary and two secondary heat transfer loops. The design is similar to a previous design, the SmAHTR (Carbajo 2010; Greene 2010), with 3 loops, 3 DRACS, and a power of 125 MWt. The demonstration reactor has 2 loops, 2 DRACS, and a power of 100 MWt. The SmAHTR is an integral reactor, while the demonstration reactor is not. Because of the similarities, the FHR DR RELAP5-3D models were derived from the RELAP5-3D models of the SmAHTR concept. 


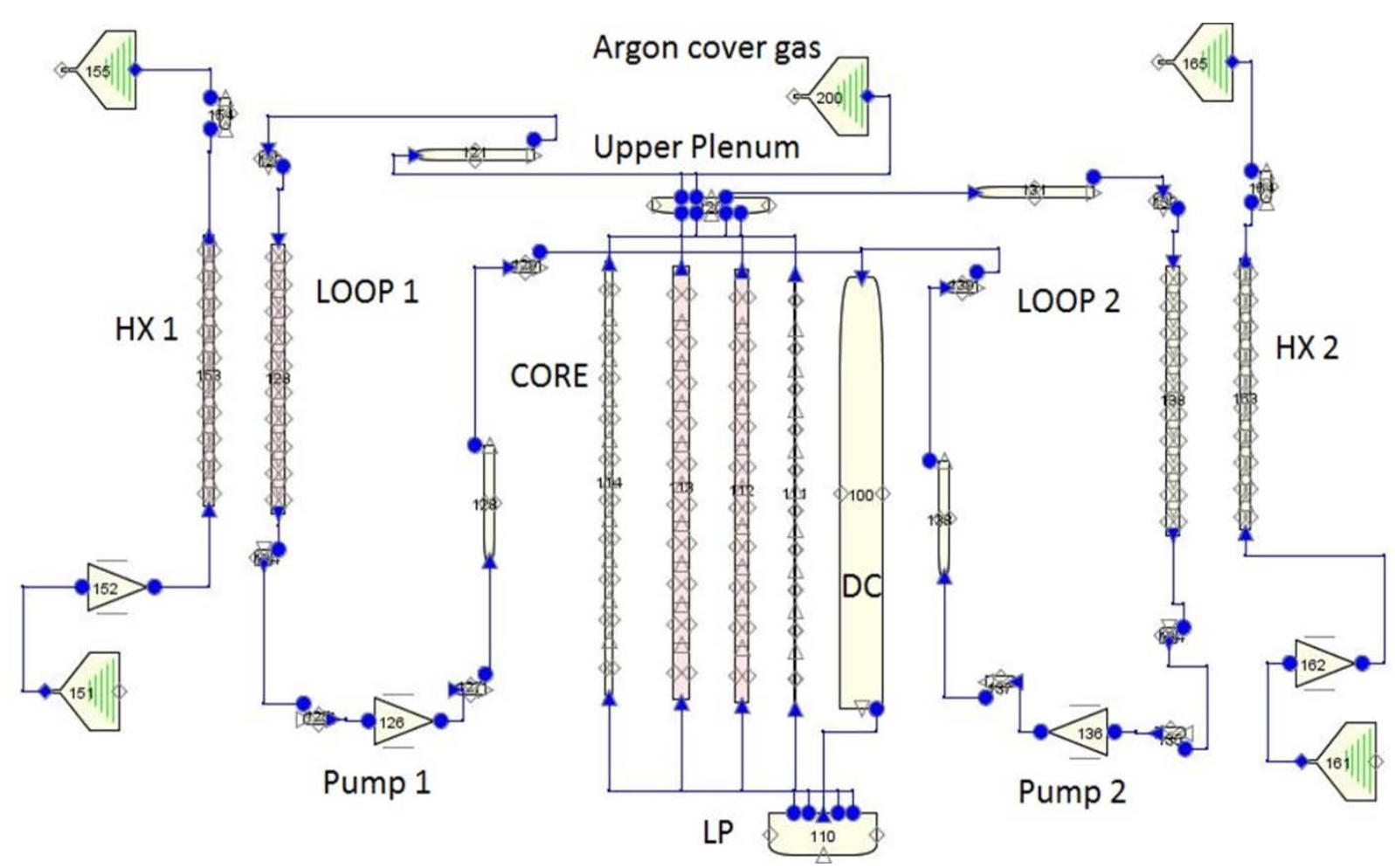

Fig. 13. RELAP5-3D nodalization employed for the complete reactor system.

The primary system employs FLiBe as the coolant, and the intermediate system and the two DRACS loops employ FLiNaK (47 mol\% LiF, $11 \mathrm{~mol} \% \mathrm{NaF}$, and $42 \mathrm{~mol} \% \mathrm{KF}$ ) as the coolant. The primary system includes the lower plenum, four core channels, the upper plenum, piping, two pumps, and two heat exchangers. The upper plenum is connected to a volume containing argon at atmospheric pressure. This volume controls the pressure in the system. The core is modeled with four hydraulic channels. Each pipe consists of 10 axial nodes. The first and the last nodes are in contact with the bottom and upper reflector of the core. The central 8 nodes are in contact with the fueled part of the core. The first pipe models the central graphite block and consists of 9 cooling channels. The second pipe models the first ring of 6 fuel assemblies with a total of $(6 \times 109) 654$ cooling channels. The third pipe models the second ring with 12 fuel assemblies and a total of $(12 \times 109) 1308$ cooling channels. The fourth pipe models the graphite reflector and has a total of 187 cooling channels. The diameter of one cooling channel is $1.2 \mathrm{~cm}$. Although no heat is assumed to be generated in the graphite, cooling channels have been provided in the graphite blocks. The total number of cooling channels in the fuel assemblies is $(18 \times 109) 1,962$, and 196 cooling channels $(\sim 10 \%$ of the fuel assembly channels) are provided to the unfueled graphite blocks, with 9 channels in the central block and 187 channels in the reflector blocks at the core periphery. These coolant channels are provided in anticipation of heat generated in the unfueled graphite blocks and to prevent overpredicting flow in the other channels.

The fuel is modeled as cylindrical structures $1.247 \mathrm{~cm}$ in diameter surrounded by a graphite annulus that is $0.6236 \mathrm{~cm}$ thick. The graphite annulus is in contact with the cooling channels. The fuel is modeled with 8 axial nodes, $32.7 \mathrm{~cm}$ high each. One assembly block, which is $65.3 \mathrm{~cm}$ high, is modeled with two axial nodes. Additional structures are employed to model the remaining graphite in the assemblies and the graphite blocks without fuel. Heat is generated in the fuel only, and the power is applied in the axial direction following a heat generation curve from the neutronic calculation with a power peak of 1.27. 
The pipes employed in the loops are $0.254 \mathrm{~m}$ inner diameter (ID) (10 in. ID). There are two intermediate loops, one for each heat exchanger. There are also two DRACSs, one passive and one active. The heat removal capacity of the passive DRACS is between $0.5 \%$ and $0.7 \%$ of the total reactor power $(0.5-0.7 \mathrm{MW})$. The heat removal capacity of the active DRACS is still under investigation but is expected to range from $1 \%$ to $2 \%$ of the total reactor power. Two (2) MW is thought to be higher than necessary, but it would provide some safety margin. The passive DRACS has a cooling loop with a heat exchanger inside the downcomer and another heat exchanger inside an outdoor cooling tower cooled by air. Both the FLiNaK coolant inside the loop and the air in the cooling tower are circulated by natural convection in the passive system.

The active DRACS has a heat exchanger inside the downcomer and another heat exchanger outside the reactor. The FLiNaK coolant is circulated in this DRACS by an electric pump (active system). This active DRACS system has a higher heat removal capacity than the passive DRACS because the pump can circulate more coolant inside the DRACS loop. The active system pump is operated by a battery system and backup generating system in the event of a loss of plant power. The use of an active DRACS allows the FHR DR to more directly receive regulatory approval and the FHR DR will become a test bed for testing the passive system.

The RELAP5-3D model illustrated in Fig. 12 does not have either the passive or active DRACS incorporated. In this model, each primary pump provides a flow of $524 \mathrm{~kg} / \mathrm{s}$ (1048 kg/s total) and results in a pressure drop through the core of $60 \mathrm{kPa}$. The maximum calculated temperature of the fuel under steady state conditions at full power is $\sim 900^{\circ} \mathrm{C}$. (The RELAP5-3D model is a simplified model, so the temperatures calculated by the COMSOL models are different.) The calculated coolant velocity in the fuel coolant channels is $\sim 2.22 \mathrm{~m} / \mathrm{s}$.

When the DRACSs are incorporated into the model, two heat exchangers (one for each DRACS) at the top of the downcomer and two flow paths connecting the downcomer and the upper plenum are also incorporated. These flow paths allow for natural convection flow to be circulated from the upper plenum to the downcomer (and to the lower plenum and into the core) when the system pumps are not operating. During normal operation with the pumps on, some flow from the downcomer will be diverted to the upper plenum; a penalty to pay for having DRACSs. A diode valve is installed in these flow paths with a high resistance for the flow from the downcomer to the upper plenum and with a low resistance for the flow in the opposite direction. The diode valves minimize these parasitic flows during normal operation and allow for the natural convection flows when the pumps are not operating. The passive DRACS has an estimated power loss of $\sim 0.2 \mathrm{MW}$ during normal operation, as flow is continuously circulated in this loop. The active DRACS is assumed to have no power losses during normal operation, as the pump of this loop is not activated. However, both DRACSs have flow losses from the downcomer to the upper plenum, as both DRACSs have some flows connecting these volumes. The amount is dependent upon the effectiveness of the diode valves.

For the assumed diode valve performance, during steady state operation with the DRACS incorporated, RELAP5 calculated parasitic flows of $9.3 \mathrm{~kg} / \mathrm{s}$ from the downcomer to the upper plenum $(1.8 \%$ of the pump flow of $524 \mathrm{~kg} / \mathrm{s}$ ) for each DRACS. Since the flow through the core is reduced by $9.3 \times 2=18.6 \mathrm{~kg} / \mathrm{s}$ from the model without DRACS, the pressure drop through the core is reduced to $58.8 \mathrm{kPa}$.

A loss of forced flow (LOFF) with scram transient calculation was performed to evaluate the effectiveness of the passive DRACS. The system is operating at the full $100 \mathrm{MWt}$ power at $150 \mathrm{~s}$ when the reactor scrams and the pumps are turned off. The pumps reach zero flow in $\sim 40 \mathrm{~s}$, and the reactor power is reduced to decay heat levels within $\sim 2 \mathrm{~s}$. With the active DRACS not operating, the passive DRACS removes $\sim 0.7 \%$ of the initial power $(0.7 \mathrm{MW})$. Fig. 14 shows the calculated temperatures at the exit of the core and at the upper plenum. Maximum coolant temperature is $\sim 770^{\circ} \mathrm{C}$, and both temperatures decrease after $\sim 35,000 \mathrm{~s}$. Fig. 15 shows the calculated flows through the DRACS. The flows reverse from $-9.2 \mathrm{~kg} / \mathrm{s}$ before the transient (with the pumps on) to $2.2 \mathrm{~kg} / \mathrm{s}$ in the passive DRACS and near zero in the active DRACS which is not operating. 
If the active DRACS is operating and removing 1-2 MW of decay heat, lower coolant temperatures will result.

The system response to a LOFF without the use of the active DRACS is relatively benign, with peak salt temperatures staying below $770^{\circ} \mathrm{C}$ and peak fuel temperature staying below $950^{\circ} \mathrm{C}$. The transient is slow to evolve, allowing substantial time to restore forced circulation. If forced circulation is not restored, the system steadily cools over a period of many days.

In general, the temperature response of the system to a LOFF is very similar to that previously analyzed for the SmAHTR (Carbajo et al. 2010). These results indicate that the demonstration reactor would be able to prove the efficacy of the DRACS, which is a key safety feature in a number of the proposed FHR designs. Future transient calculations are planned with transients with point kinetics or nodal kinetics to investigate the neutronics/TH feedback.

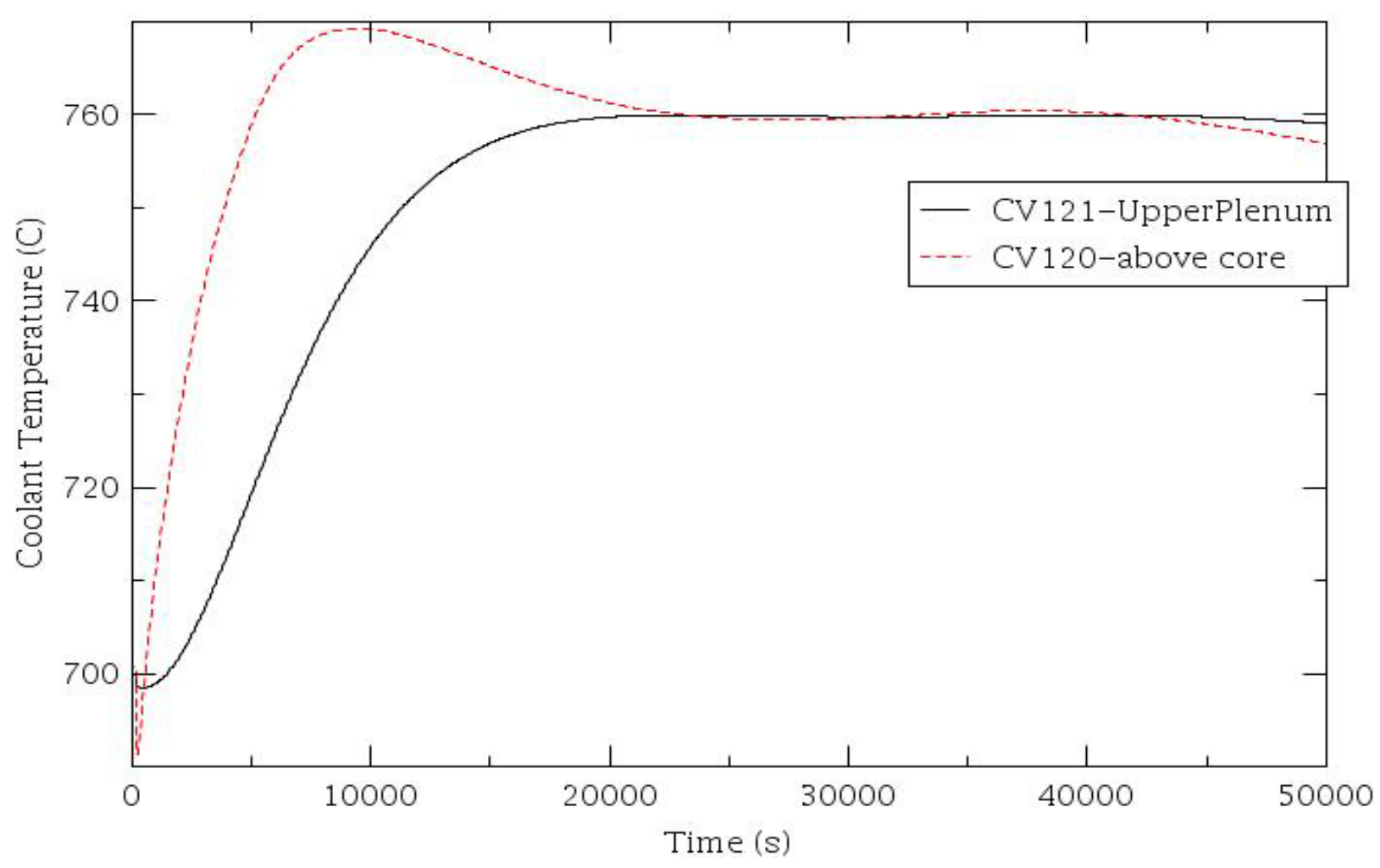

Fig. 14. RELAP5-3D calculated coolant temperatures after a LOFF with use of the passive DRACS. 


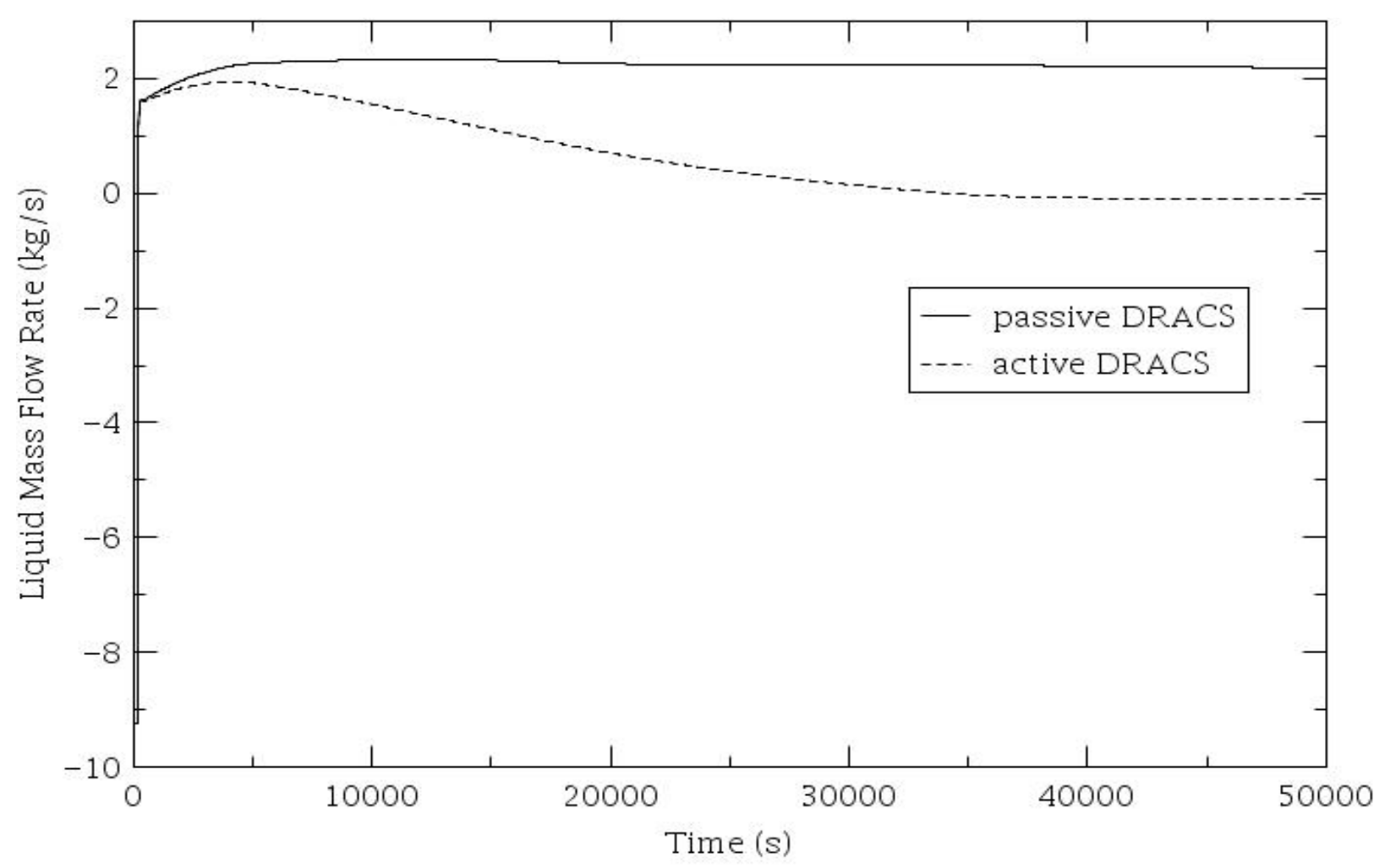

Fig. 15. RELAP5-3D calculated flows through the two DRACS (passive and active).

\subsection{PRIMARY SYSTEM SALT COOLANT AND TRITIUM MANAGEMENT}

Fig. 16 shows the FHR DR core and vessel. The reactor core is located within a pool of primary coolant under forced flow. Within the vessel, a core barrel constrains the core and forms a downcomer region along the inner surface of the vessel wall. The core barrel prevents mixing and reduces heat transfer between the cooler incoming primary coolant and the hotter coolant exiting the top of the core. The nominal thermal power of the FHR DR is $100 \mathrm{MWt}$, and the temperature increase across the core is $40^{\circ} \mathrm{C}$. The maximum mixed mean reactor coolant outlet temperature is $700^{\circ} \mathrm{C}$. An upper limit of $700^{\circ} \mathrm{C}$ can be reasonably assumed for either alloy $800 \mathrm{H}$ and alloy $\mathrm{N}$ (Ren et al. 2011). These alloys are the materials of the reactor vessel, as well as the primary and intermediate heat transfer systems. 


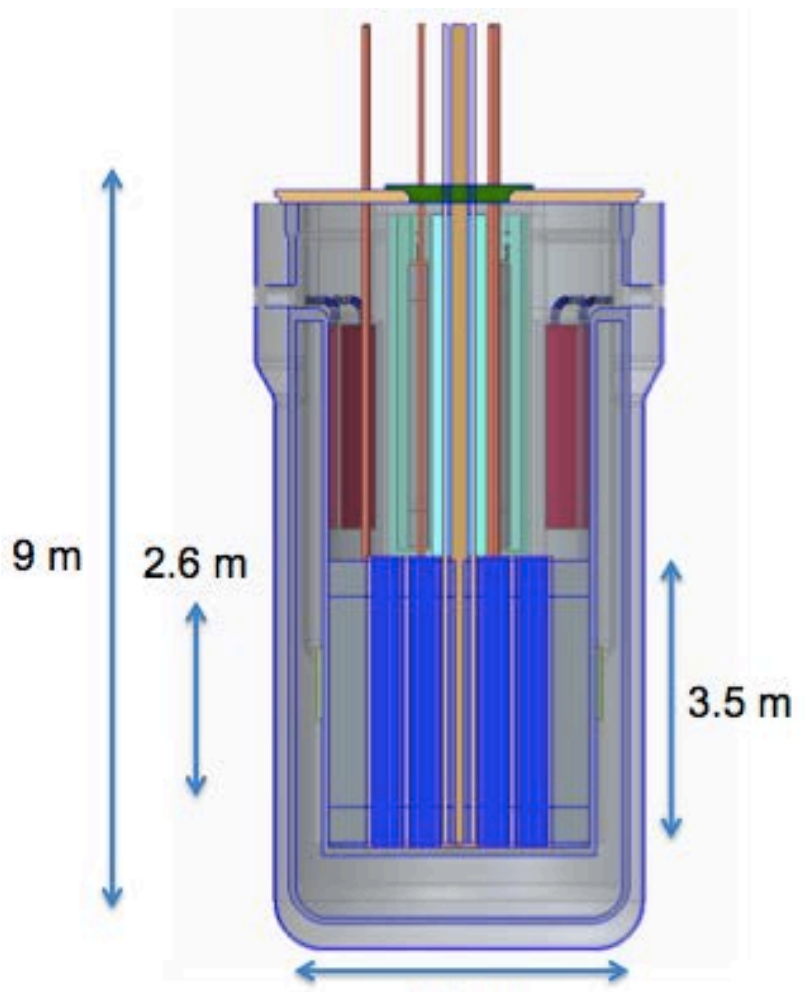

$4.1 \mathrm{~m}$

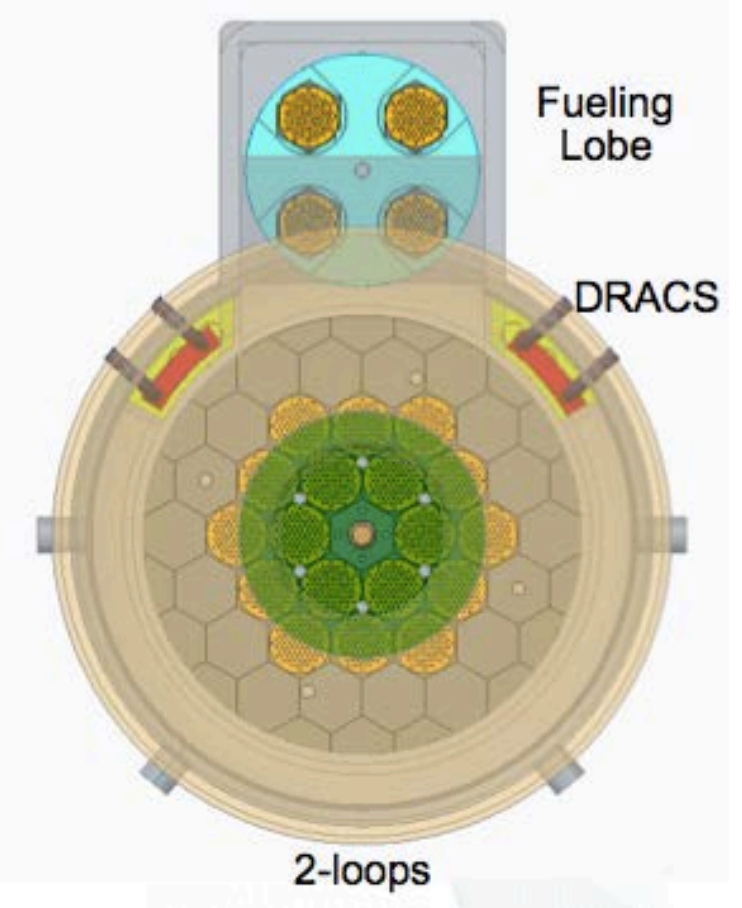

OAK RIDGE

Fig. 16. Elevation view of the FHR DR showing the reactor core within the vessel.

FLiBe features relatively attractive coolant properties and is also a neutron moderator. This combination results in coolant temperature and void coefficients that are either negative or negligible, which makes it the coolant of choice for many commercial concepts. A challenge with FLiBe coolant is the production of tritium $\left({ }^{3} \mathrm{H}\right)$, a radioactive isotope of hydrogen. An economically attractive and technically viable tritium management solution is necessary for the commercial deployment of FHRs, and a vital role of the FHR DR is to enable in-situ technology readiness level (TRL) advancement of tritium management technologies. Tritium is produced largely due to radioactive transmutation of ${ }^{6} \mathrm{Li}$, which can itself be produced through beryllium transmutation. The tritium production rate is highest when the concentration of ${ }^{6} \mathrm{Li}$ is highest and initial and equilibrium tritium production rates in an FHR are therefore different. Whether the higher rates occur at equilibrium or during initial operation depends on the initial enrichment of ${ }^{7} \mathrm{Li}$.

One potential FHR DR tritium management technology is derived from MIT, its partners at UCB, and the University of Wisconsin-Madison. The approach is to getter tritium using a packed bed of spheres within the primary system outside the reactor core. A fraction of the spheres is periodically removed and heated to drive off the gettered tritium. In the FHR DR, all coolant that leaves the core enters one of two tritium management test locations that house the packed beds. The testing stations are located in each primary coolant hot leg between the vessel outlet and the primary-to-intermediate heat exchangers. The packed bed serves as a test bed for various gettering materials, including low cost non-nuclear-grade graphite. The ability to use non-nuclear-grade graphite is one potential advantage of having the tritium removal system external to the core. However, many uncertainties remain about this technology, and it requires further investigation. Another near-term tritium management technology option is to use a double walled primaryto-intermediate heat exchanger with an interstitial sweep gas and possibly with an interstitial getter. It is not yet clear which tritium management solution would perform best or be the most attractive in a large FHR. However, both the packed bed of gettering spheres and the double walled heat exchanger with a sweep gas are credible approaches that could be implemented as baseline tritium management solutions in the FHR DR. 
The FHR DR will be able to assess and demonstrate—on a reactor scale—-the synergistic effects of multiple tritium management and coolant chemistry control solutions. These solutions have various levels of maturity, but some of the most promising options have lower technology readiness. Building and operating the FHR DR is an important step to maturing and demonstrating these important technologies.

\subsection{REACTOR VESSEL}

A top view of the FHR DR vessel and core is shown in Fig. 17. It shows the top of the reactor core and the locations of control rods and instrumentation ports, the core barrel defining the downcomer region, and the DRACS heat exchangers in isolated sections of the downcomer. A refueling lobe extends off of one side of the vessel, but it is not shown in this view. Incorporating design features common to the AHTR, SmAHTR, and the Mk1 concepts, the thin-walled vessel is suspended by a flange within a reactor silo. To keep the vessel wall temperature low, the primary coolant enters the reactor vessel through downcomer sections (defined by a core barrel) that direct the cold-leg coolant flow down to a lower plenum. The coolant flows up from the lower plenum to cool the fuel and core support structure.

Primary coolant enters the vessel at two inlet ports and is withdrawn from two outlet ports. Between the two downward flowing downcomer regions, two smaller sections house the DRACS heat exchangers. The salt coolant inside the DRACS heat exchangers is independent and isolated from the reactor primary coolant. One DRACS heat exchanger is part of an active safety system to remove decay heat from the system during LOFF or loss-of-offsite-power (LOOP) events. The other is part of a passive DRACS. A removable top hatch covers the vessel. Within the central portion of the top hatch, a smaller removable hatch houses the control drive mechanisms. The control drive systems can be readily adapted from other high temperature reactor development activities and are not the focus of the FHR DR design effort.

Removal of the smaller hatch, including the control drive mechanisms, allows for the insertion of a fuel manipulator for maneuvering of fuel within the vessel. The full top hatch can be completely removed for more extensive in-vessel modifications, including complete core exchange. New removable top hatch designs can be installed to facilitate new core designs or to allow access to new operating features such as flux traps or irradiation locations within the unfueled central or peripheral positions. 


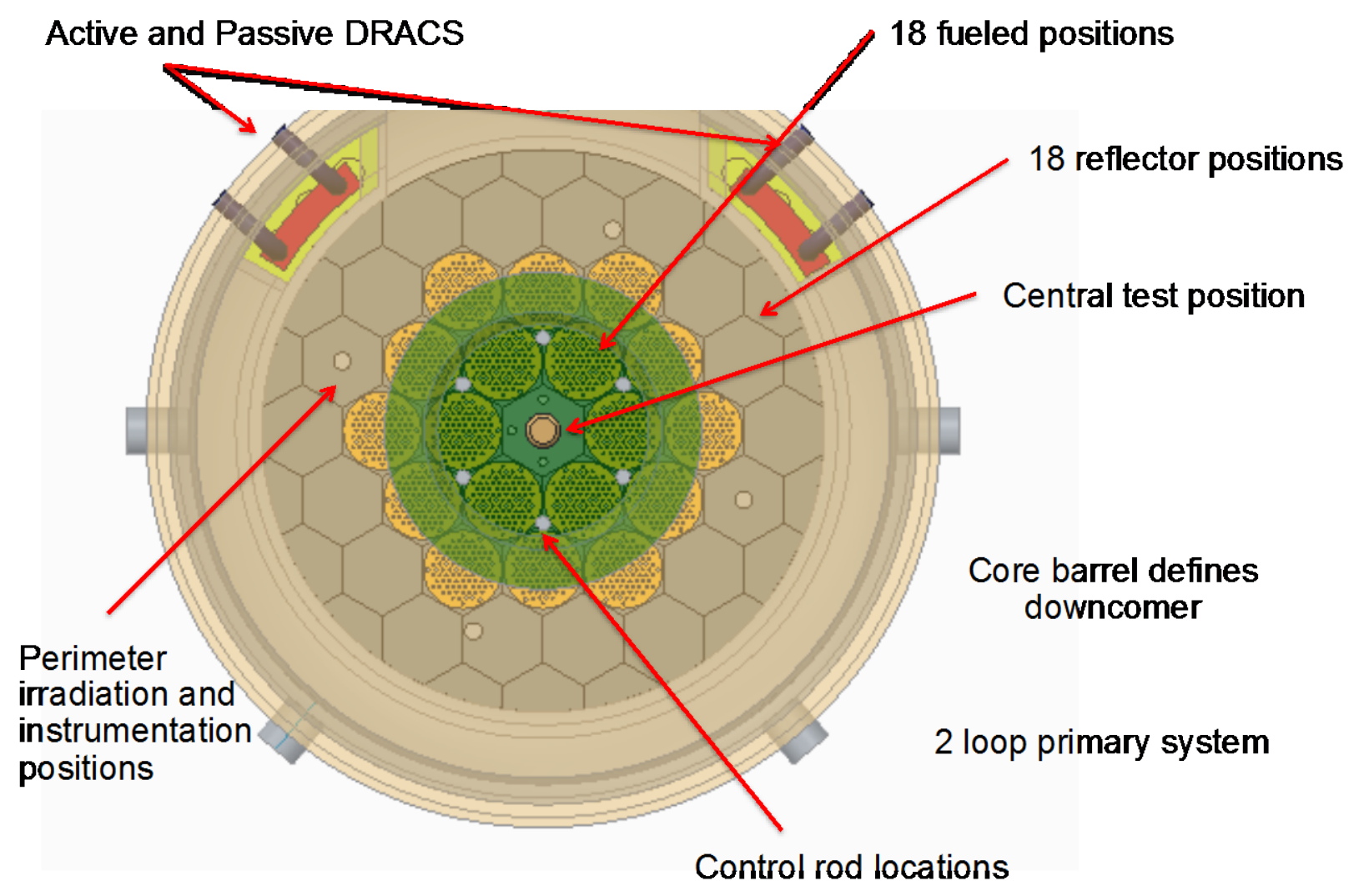

Fig. 17. Top view of the FHR DR core and vessel.

\subsection{HEAT TRANSPORT CONFIGURATION AND LAYOUT}

The heat transport systems consist of four salt pumps, two primary-to-intermediate salt-to-salt heat exchangers and the associated primary and intermediate loop piping. Tritium management experiment stations are located between the reactor vessel and the primary-to-intermediate heat exchangers. Features of the PHTS are listed in Table 3. The FHR DR uses alloy $800 \mathrm{H}$ lined with alloy $\mathrm{N}$ as structural materials for the primary and intermediate loops. The primary-to-intermediate heat exchangers are made from the same material combination. The use of similar materials throughout the system avoids the additional cost, complexity and uncertainty of developing and operating high temperature dissimilar metal heat transfer systems. The FHR DR incorporates tube-and-shell salt-to-salt heat exchangers because it is a relatively lowrisk technology. Tube-and-shell technology also allows for a swept interstitial region to be incorporated between the salts in a double-walled heat exchanger to limit tritium migration from the primary system to the intermediate system. 
Table 3. PHTS

\begin{tabular}{|c|c|c|}
\hline Parameter & Unit & Value \\
\hline Reactor thermal power & MWt & 100 \\
\hline $\begin{array}{l}\text { Targeted net thermal efficiency of derived commercial } \\
\text { application }\end{array}$ & $\%$ & 45.0 \\
\hline Primary coolant (Phase II) & & $2^{7} \mathrm{LiF}-\mathrm{BeF}_{2}$ \\
\hline Lithium-7 enrichment level & $\%$ & 99.995 \\
\hline Fuel type & & $\mathrm{UC}_{0.5} \mathrm{O}_{1.5}$ coated particle \\
\hline${ }^{235} \mathrm{U}$ enrichment level & $\%$ & 15.5 (baseline) \\
\hline Reflector material & & Graphite \\
\hline Reactor vessel internals material & & Alloy N \\
\hline Core structural material & & C-C composite \\
\hline Control blade material & & MHC alloy \\
\hline Primary coolant flow rate & $\mathrm{kg} / \mathrm{s}$ & $\sim 1000$ \\
\hline Number of primary loops & & 2 \\
\hline Refueling interval & Months & $12-18$ \\
\hline Fuel format & & $\begin{array}{l}\text { Prismatic block with coolant } \\
\text { channels and fuel compacts }\end{array}$ \\
\hline Mixed mean core outlet temperature & ${ }^{\circ} \mathrm{C}$ & 700 \\
\hline Core inlet temperature & ${ }^{\circ} \mathrm{C}$ & 660 \\
\hline Number of fuel assemblies & & $\begin{array}{l}18 \text { fueled (baseline core, } \\
\text { configuration is flexible) }\end{array}$ \\
\hline Maximum fuel temperature (average assembly) & ${ }^{\circ} \mathrm{C}$ & 973 \\
\hline Vessel material (Phase I/Phase II) & & Alloy N \\
\hline Core fueled height & $\mathrm{m}$ & 2.61 \\
\hline Core pressure drop for normal operation & atm & 0.6 \\
\hline
\end{tabular}

Consistent with the ORNL AHTR and SmAHTR concepts, the baseline salt for the intermediate heat transfer loop is FLiNaK, which was chosen as a compromise among heat transfer performance, melting temperature, handling issues, and cost. FLiNaK is also used in the DRACS for similar reasons, as well as the desire to limit the number of salt compositions used at the facility. The features of the intermediate heat transport system are listed in Table 4.

Table 4. Intermediate heat transport system

\begin{tabular}{lll}
\hline \multicolumn{1}{c}{ Parameter } & Unit & \multicolumn{1}{c}{ Value } \\
\hline Thermal power & MWt & 95 \\
Intermediate coolant & & FLiNaK \\
Coolant flow rate & $\mathrm{Kg} / \mathrm{s}$ & $\sim 1000$ \\
Power cycle fluid & & air \\
\hline
\end{tabular}

\subsection{REACTOR SILO}

The FHR DR reactor vessel is housed in a reactor silo similar to the AHTR reactor silo shown in Fig. 18; the FHR DR silo and reactor buildings are still under development. The silo is the central feature of the FHR DR reactor building. It provides support and protection for the reactor vessel and serves critical operational and 
safety functions. The melting point of the primary coolant is $\sim 459^{\circ} \mathrm{C}$. To minimize the energy required to maintain melt temperatures, the vessel is surrounded by heaters and insulation and is thermally isolated from the surrounding concrete by a dry inert gas-filled gap as shown in Fig. 19. The silo is lined with stainless steel, which serves as the secondary containment for primary salt if the vessel leaks.

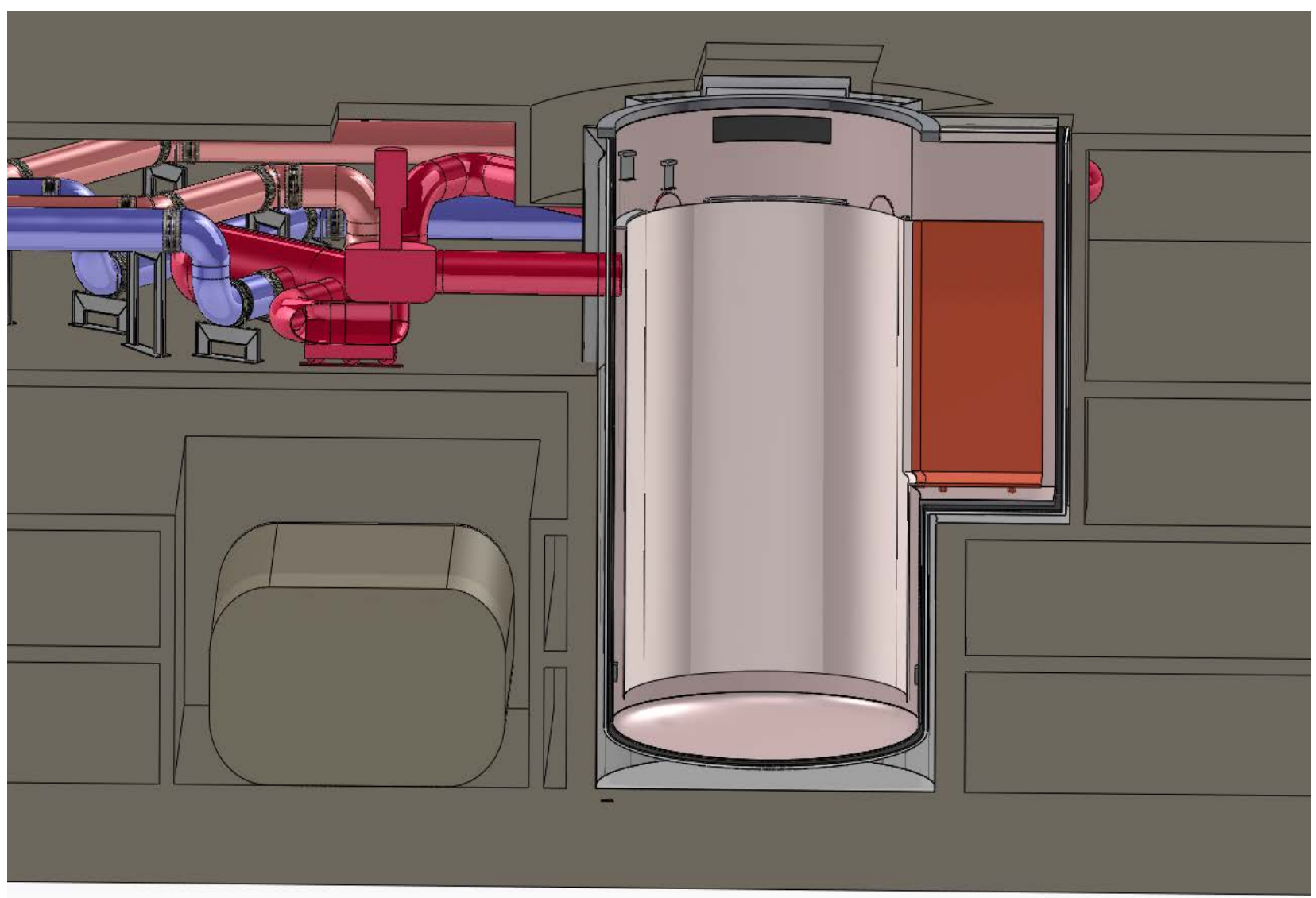

Fig. 18. View of primary system piping within the AHTR reactor building (a similar approach is being pursued with the FHR DR). 


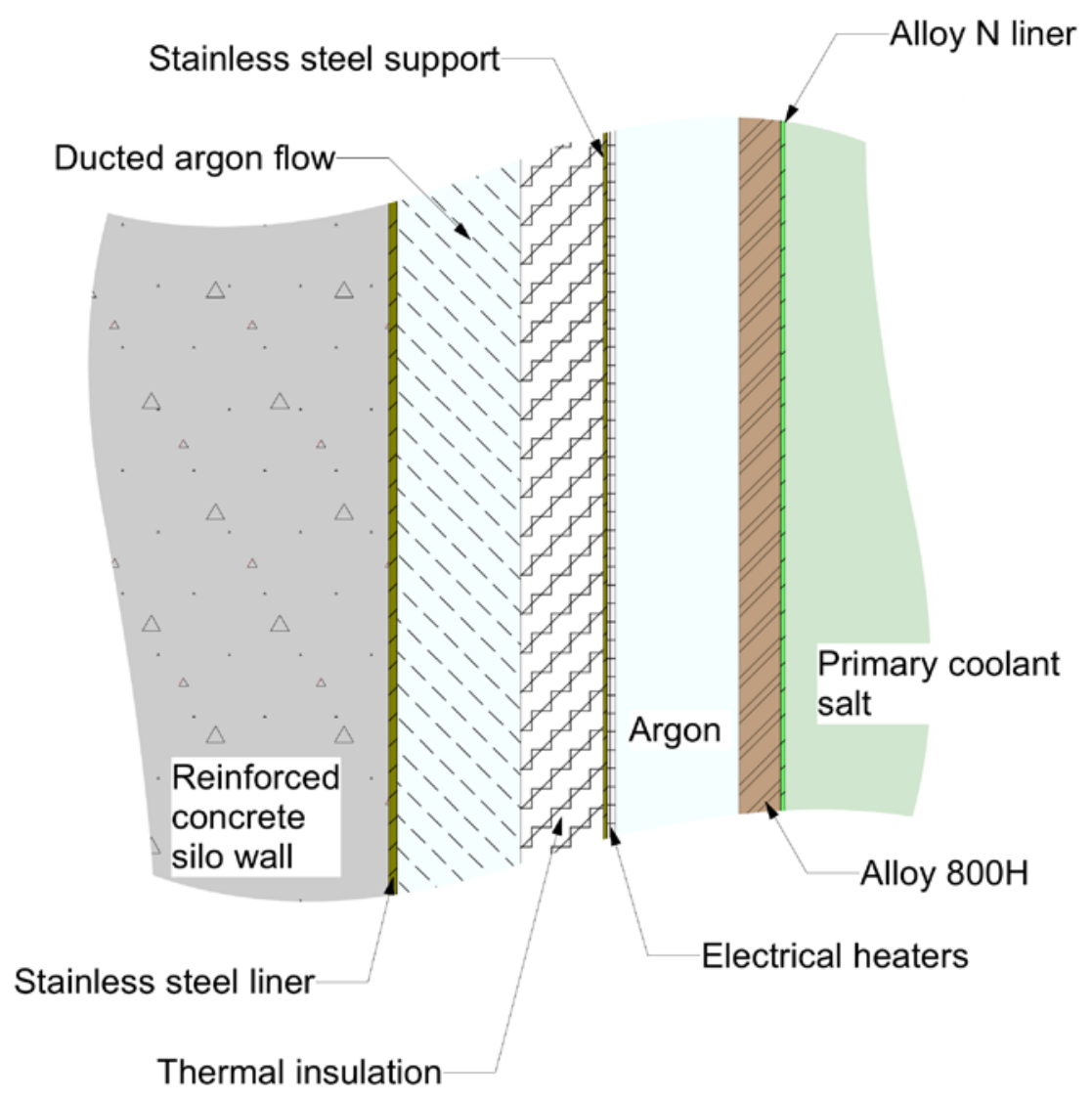

Fig. 19. Notional arrangement of the reactor vessel and thermal blanket within a reactor silo.

Additional resistance heaters warm ex-vessel structural components, and coolant pumps add heat directly to the salts when the reactor is not operating. Salt flow distributes heat throughout the system. The vessel and heat transport systems must be protected if electrical power to the plant is lost. This is accomplished with auxiliary electrical generating equipment to cover short periods without grid power, and failsafe shutdown designs and methods are used for extended outages.

\section{REACTOR BUILDING AND AUXILIARY REACTOR SYSTEMS}

The reactor building houses the balance of the primary system one floor level below the reactor bay floor. The primary-to-intermediate heat exchangers, tritium experimental areas, and primary coolant pumps are housed on this lower level. Reactor fuel is staged on the main floor of the reactor building, and spent fuel is stored in an isolated salt tank away from the vessel.

The top hatch plug and the control drive mechanisms are removed and stored in the bay during fueling operations. A crane-hoisted fuel transport cask is used to move fuel block assemblies within the reactor building. Fresh fuel block assemblies are stored in criticality control areas on the bay floor. Fuel is inserted into and removed from the vessel through the refueling lobe, and the fuel manipulator moves fuel between the lobe and the core. 
The fuel transport cask positions fuel blocks over openings in the top of the refueling lobe. Fresh fuel blocks are lowered into empty cylindrical positions within a rotating carousel in the lobe. The carousel has vertical openings large enough to pass fuel blocks from the lobe into the vessel. During operation, the carousel is rotated to place a solid surface toward the core to complete the surface of the core barrel. This isolates fuel in the lobe from fuel in the core and allows, but limits, primary salt mixing between the lobe and the vessel.

To remove spent fuel, the carousel is rotated to expose an empty location to the vessel. The fuel manipulator moves spent fuel into the carousel, which is then rotated to actively capture the fuel and isolate it from the vessel and core. Rotating the carousel further exposes a location filled with a fresh fuel block, and the fuel manipulator places the block in the correct core location. The fuel transport cask is maneuvered over the refueling lobe, and a single spent fuel block is pulled into the cask. Once secured, the spent fuel is moved over and lowered into an isolated salt storage vault on the reactor bay floor until it can be removed to semipermanent dry storage at the reactor site. The fuel removal system from the AHTR design is shown in Fig. 20.

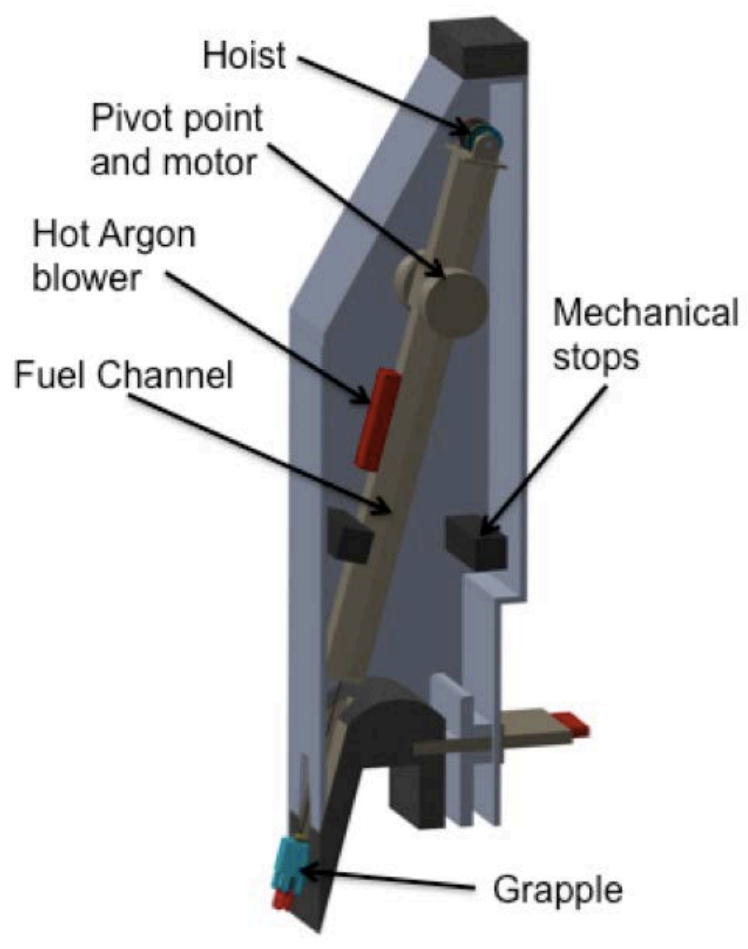

Fig. 20. Used fuel removal system.

Piping passes out of the reactor primary system areas where radiation is higher and into an adjacent area which houses the balance of the intermediate heat transport system and heat use equipment, as seen in Fig. 21. The waste heat rejection system is outside of the heat handling area. Heated intermediate salt is deposited into an insulated storage vessel. It is possible to withdraw energy from this salt vessel and use it in a number of ways. High temperature forced-air heat exchangers to drive open-air Brayton cycle power systems are the reference baseline for what could eventually be an electrical generation application. Other high-temperature heat processes can be driven by placing salt-to-salt heat exchangers directly into the salt storage vessel. Lower temperature steam production can potentially occur to produce electricity or drive a steam-based chemical process or heat can also simply be rejected using the cooling tower when other capabilities are not being demonstrated. The PB-FHR reactor concept directly coupled to an open-air Brayton cycle is also 
shown in Fig. 21, This is the reference baseline power conversion technology for the FHR DR which could produce an estimated 42 MWe in this configuration.
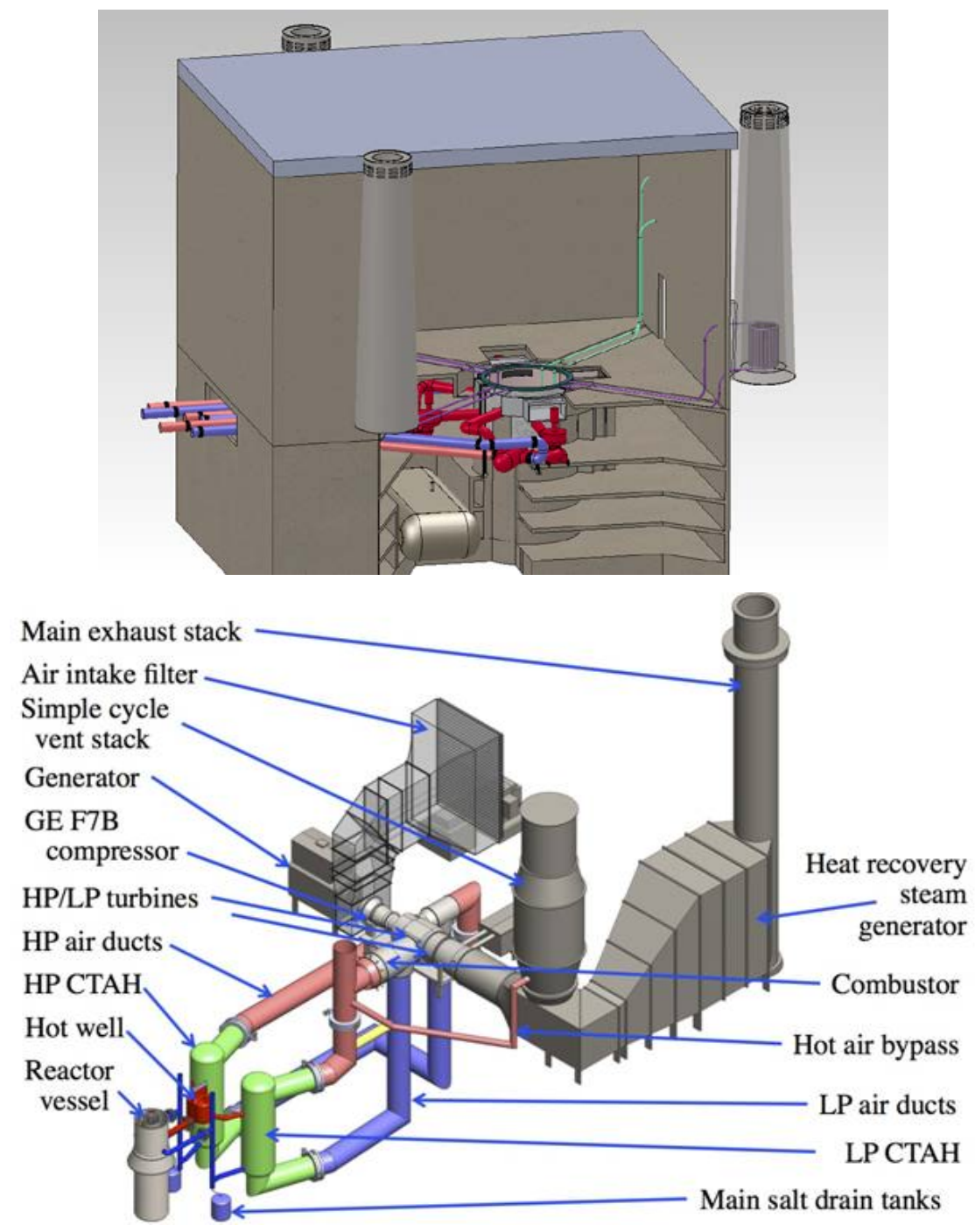

Fig. 21. Intermediate piping passing out of the reactor building (above) and into an adjacent building housing the intermediate transport system and power dissipation equipment (below) (Forsberg et al. 2014a).

\section{SAFETY BASIS}

Active safety systems are used to accelerate licensing the FHR DR in the near-term because adequate data do not exist to prove performance of passive salt-based heat removal safety systems for licensing purposes. The FHR DR will in fact use active systems to allow operation that will generate the needed data and demonstrate passive safety systems for commercial deployment of passively safe FHRs.

The active safety heat removal systems for the FHR DR are the two primary loops and two intermediate loops with electrical backup for the pumps and the active DRACS system, which also has electrical backup. 
The passive system primarily considered for decay heat removal in the FHR-DR is DRACS. DRACS cool the primary coolant directly using an in-vessel heat exchanger. The FHR DR uses an active (forced flow) DRACS system to ensure safe removal of decay heat. However, the FHR DR also has the capacity to demonstrate a passive DRACS system in a nearly identical configuration, as shown in Fig. 22. The DRACS relies on flow restriction under normal operating conditions to limit upward bypass flow from the lower plenum to the upper plenum. When the DRACS is in use, the flow over the heat exchangers reverses, and warm coolant flows downward in the DRACS downcomer sections. Passive flow restrictors, seen below the DRACS heat exchangers (yellow) in Fig. 22, require development and testing.

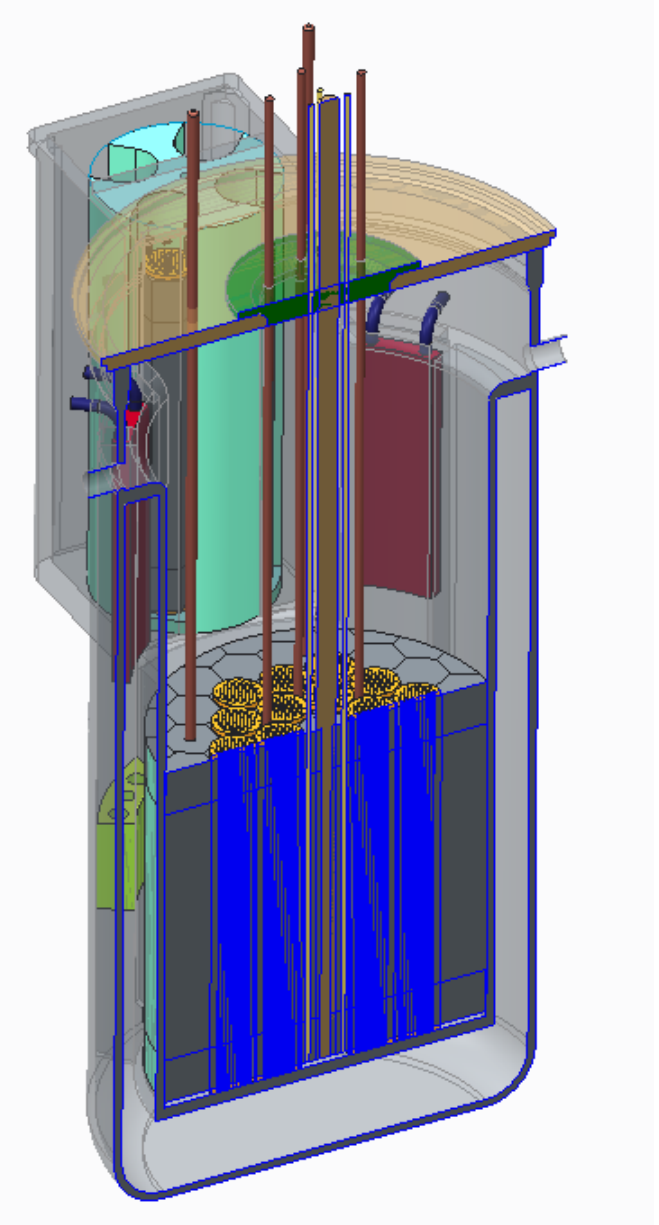

Fig. 22. FHR DR vessel showing DRACS heat exchangers (red). One heat exchanger will be used as an active safety system and the other is included to allow for passive heat removal demonstrations.

\section{CONCLUSIONS}

The FHR DR will significantly advance FHR technology towards the realization of a first-of-a-kind commercial facility. The design relies on lower risk near-term technologies to ensure deployment within an estimated 10 years. It is a thoroughly instrumented demonstration to validate performance and safety codes, as well as high-fidelity advanced simulation tools. Technology needs such as tritium management will be developed for and demonstrated in the FHR DR. Where possible, the facility will be designed to allow for multiple solutions to remaining FHR technical challenges. 
The FHR DR fuel form was selected based on an assessment of the potential for deployment within 10 years. The fuel form is based on the well-understood prismatic graphite block with integral coolant channels and fuel compacts. However, the FHR DR is designed to advance other fuel concepts such as plank-based fuel as needed. This is accomplished via a fuel-testing zone in the center of the core, which enables testing of instrumented test assemblies or their equivalent. Pebble fuel can be qualified in the FHR DR, although the bed of pebbles would be fixed. Pebble handling is already under test in a non-nuclear facility at UCB. Fuel forms based on high density, high thermal conductivity ceramic materials (such as $U \mathrm{UN}^{-} \mathrm{U}_{3} \mathrm{Si}_{5}$ or $\mathrm{U}_{3} \mathrm{Si}_{2}$ ) with advanced cladding (SiC-SiC or molybdenum-based systems) can be tested in the FHR DR. These advanced fuel forms, under development by DOE-NE Advanced Fuel Campaign, may offer advantages related to the fuel cycle, and preliminary analysis suggests they would be suitable in an FHR DR design.

FHR DR design features are taken from several concepts, including the ORNL AHTR and SmAHTR concepts, the MIT FHR Test Reactor, and the UCB Mk1. The FHR DR technology is most representative of the $3400 \mathrm{MWt}$ AHTR concept, and it will demonstrate key operational features of that design. The major functions necessary to operate an FHR that are demonstrated by the FHR DR include salt handling, fuel handling, pumping and heat exchange, tritium management and safety system response.

The FHR DR point design is preliminary at this writing and work continues to refine both the reactor and the balance of the facility for a completed point design in January 2016.

\section{REFERENCES}

C. Andreades, A. T. Cisneros, J. K. Choi, A. Y.K. Chong, M. Fratoni, S. Hong, L. R. Huddar, K. D. Huff, D. L. Krumwiede, M. R. Laufer, M. Munk, R. O. Scarlat, N. Zweibaum, E. Greenspan, P. F. Peterson, "Technical Description of the "Mark 1" Pebble-Bed Fluoride-Salt-Cooled High-Temperature Reactor (PB-FHR) Power Plant," University of California-Berkeley-UCBTH-14-002, University of CaliforniaBerkeley, Berkeley, CA., December 2014.

AREVA NP Inc., Evaluation of the LS-VHTR Concept, AREVA NP Inc. under BEA Contract No. 00045559, AREVA NP Inc., Lynchburg, VA., September 2007.

S. Bragg-Sitton, R. Boardman, et al., Integrated Nuclear-Renewable Energy Systems: Foundational Workshop Report, INL/EXT-14-32857 Rev. 1, NREL/TP-6A20-62778, August 2014.

J. J. Carbajo, et al, "Transient Thermal-Hydraulic Simulation of the Small Modular Advanced HighTemperature Reactor (SmAHTR),” Trans. Am. Nucl. Society 103, Las Vegas, Nevada, November 2010.

COMSOL Multiphysics Code, http://www.comsol.com, 2015.

C. Forsberg, L.-W. Hu, J. Richard, R. Romatoski, B. Forget, J. Stempien, R. Ballinger, K. Sun, D. Carpenter, Fluoride-Salt-Cooled High- Temperature Test Reactor (FHTR): Goals, Options, Ownership, Requirements, Design, Licensing, and Support Facilities, Massachusetts Institute of Technology-ANPTR-154, Massachusetts Institute of Technology, Cambridge, MA., December 2014a.

C. Forsberg, et al., Fluoride-salt-cooled High-Temperature Reactor for Power and Process Heat: Final Project Report, Massachusetts Institute of Technology-ANP-TR-157, Massachusetts Institute of Technology, Cambridge, MA., December 2014b.

S. R. Greene et al., Pre-Conceptual Design of a Fluoride-Salt-Cooled Small Modular Advanced highTemperature Reactor (SmAHTR), ORNL/TM-2010/199, Oak Ridge National Laboratory, Oak Ridge, TN, 2010.

D. E. Holcomb et al., Core and Refueling Design Studies for the Advanced High Temperature Reactor, ORNL/TM-2011/365, Oak Ridge National Laboratory, Oak Ridge, TN, September 2011a. 
D. E. Holcomb, F. J. Peretz, and A. L. Qualls, Advanced High Temperature Reactor Systems and Economic Analysis-September 2011 Status, ORNL/TM-2011/364, Oak Ridge National Laboratory, Oak Ridge, TN, September 30, 2011b.

D. E. Holcomb et al., "Current Status of the Advanced High Temperature Reactor," Proceedings of the 2012 International Congress on the Advances in Nuclear Power Plants (ICAPP '12), Chicago, IL, June 2428, 2012.

D. E. Holcomb et al., "Fluoride Salt-Cooled High-Temperature Reactor Technology Development and Demonstration Roadmap,” ORNL/TM-2013/401, Oak Ridge National Laboratory, Oak Ridge, TN, September 2013.

RELAP5-3D Code Development Team, “RELAP5-3D Code Manuals,” INEEL-EXT 98-00834, Rev. 4.2, 2014.

W. Ren, G. Muralidharan, D. F. Wilson, and D. E. Holcomb, "Considerations of Alloy N for Fluoride SaltCooled High-Temperature Reactor Applications,” Proceedings of the ASME 2011 Pressure Vessels \& Piping Division Conference PVP2011, July 17-21, 2011, Baltimore, MD.

V. K. Varma, D. E. Holcomb, F. J. Peretz, E. C. Bradley, D. Ilas, A. L. Qualls, N. M Zaharia, “AHTR Mechanical, Structural, and Neutronic Preconceptual Design,” ORNL/TM-2012/320, , Oak Ridge National Laboratory, Oak Ridge, TN, September 2012. 


\section{APPENDIX A. DESIGN SCORING METHODOLOGY}

The design criteria and metrics established by DOE for individual goals associated with the demonstration reactor provide a means of scoring the proposed design. However, the task remains to evaluate an overall design against these multiple criteria simultaneously. The approach undertaken here includes (1) identifying key design features, (2) establishing potential options for these design features, (3) assessing the issues and risks associated with these options, (4) correlating these issues to technology readiness levels, and (5) weighting and aggregating the overall design against the metrics. The methodology is described below and has been implemented in a Microsoft Excel decision matrix spreadsheet. The spreadsheet includes several tools to evaluate and optimize design decisions, including Decision Suite's, TopRank $^{\odot}$, Evolver ${ }^{\odot}$, and PrecisionTree ${ }^{\odot}$ Excel Add-ons.

The DecisionMatrix spreadsheet will use the final DOE metrics and their respective weightings as input. The design options, issues, and TRLs in this example case are included as representative sample values only. This preliminary report provides the initial estimates for metric scoring of the design based on early judgement. The next step in the process is to establish these inputs for the first systematic evaluation of the design from which further design decisions will follow.

\section{Metric Inputs}

The fundamental inputs are the design options for the systems and components (Fig. A.1), as well as open issues that remain for each potential option. Metric grades that can be aggregated into an overall score are established for these options. DOE has established weight functions for the metrics and criteria (Figs. A.1-A.3). Design options for each applicable system/component are evaluated against these criteria and metrics.

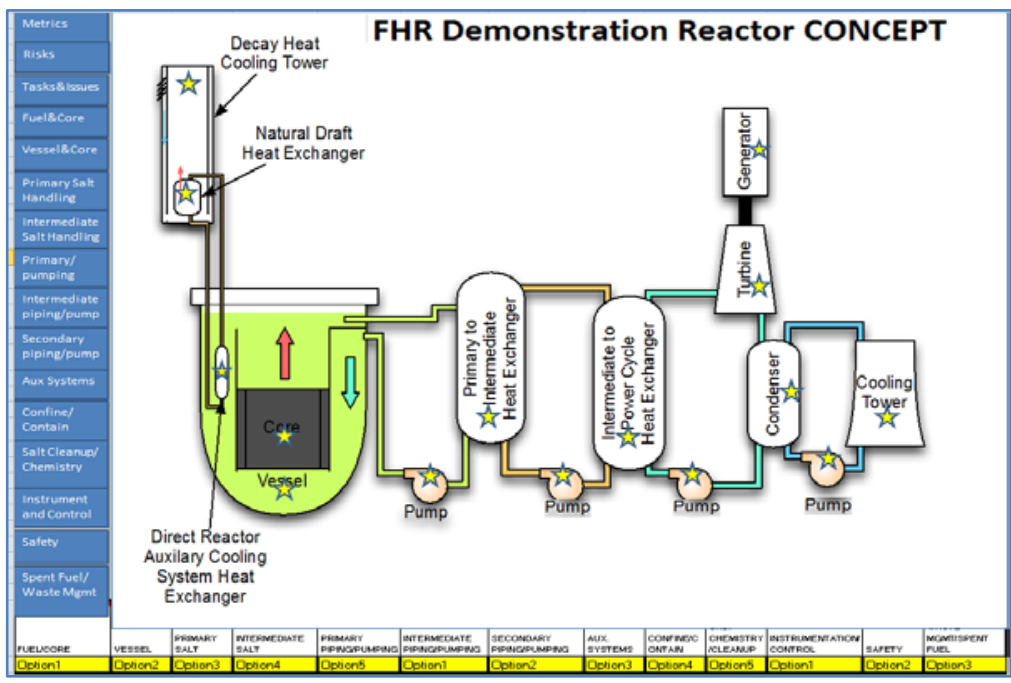

Fig. A.1. Demonstration test reactor "DecisionMatrix" spreadsheet. 


\begin{tabular}{|c|c|c|}
\hline \multicolumn{3}{|c|}{ Demonstration Reactor Goals, Criteria and Metrics } \\
\hline Goal & Criteria & Metrics \\
\hline \multirow{5}{*}{$\begin{array}{l}\text { 1. Demenstration Reactor } \\
\text { sienificantly advances the } \\
\text { technology toward a potential } \\
\text { FOAX plant }\end{array}$} & $\begin{array}{l}1.1 \text { Capability to demonstrate safety } \\
\text { behavior of commercial system }\end{array}$ & $\begin{array}{l}\text { 1.1.1 Does the demonstration system have safety characteristics and } \\
\text { systems/components expected in the commercial plant? }\end{array}$ \\
\hline & $\begin{array}{l}\text { 1.2 Detailed instrumentation and } \\
\text { data for code validation tests }\end{array}$ & $\begin{array}{l}1.21 \text { Does the desizn have adequate instrumentation and will it gather appropriate } \\
\text { data for code validation tests? }\end{array}$ \\
\hline & 1.3 Scalable technology choices & $\begin{array}{l}\text { 1.3.1 Does the desian implement technology selections that are prototypic or } \\
\text { scalable to commercial unit? }\end{array}$ \\
\hline & $\begin{array}{l}1.4 \text { Scalable maintenance techniques } \\
\text { and schedules }\end{array}$ & $\begin{array}{l}\text { 1.4.1 Does the desien have maintenance approaches that are prototypic or scalable } \\
\text { to commercial unit? }\end{array}$ \\
\hline & 1.5 Scalable fabrication options & $\begin{array}{l}\text { 1.5.1 Does the design use prototypic of scalable technologies in the fabrication of } \\
\text { important systems and components? }\end{array}$ \\
\hline \multirow{4}{*}{$\begin{array}{l}\text { 2. Demonstration Reactor } \\
\text { operations help resolve } \\
\text { technical barriers (e. } \\
\text { predictability) to advanced } \\
\text { reactor economics and reliability }\end{array}$} & \multirow{2}{*}{2.1 Construction Costs and Schedule } & 2.1 .1 Project Cont \\
\hline & & 2.2 Schedule \\
\hline & 2.2 Operational Costs and Schedule & 2.2.1 Annual Operating Costs \\
\hline & 2.3 Reliability of Operations & 2.3.1 Avaliablity factor \\
\hline $\begin{array}{l}\text { 3. Demonstration Reactor has a } \\
\text { robust Safety Design Bavis for }\end{array}$ & 3.1 Licensed by NRC & 3.1.1 Ablity to address key licensing issues for follow-on commercial units \\
\hline \multirow{8}{*}{$\begin{array}{l}\text { 4. Demonstration Reactor } \\
\text { Supports demonstration of } \\
\text { technoloey and system } \\
\text { integration (enhancing } \\
\text { immediate, intermediate and } \\
\text { lons term value of the project) }\end{array}$} & $\begin{array}{l}\text { 4.1 Facilitate component } \\
\text { demonstration }\end{array}$ & $\begin{array}{l}\text { 4.1.1 Does the system facilitate component demonstration of that expected in } \\
\text { follow on commercial units? }\end{array}$ \\
\hline & \multirow{2}{*}{$\begin{array}{l}\text { 4.2 Demonstrate alternate core } \\
\text { configurations and fuel types }\end{array}$} & 4.2.1 Number of alternative core configurations \\
\hline & & 4.2 .2 Number of alternative fuel tives \\
\hline & $\begin{array}{l}4.3 \text { Demonstrate integration with } \\
\text { various energy conversion systems or } \\
\text { industrial applications (hybrid enercy } \\
\text { systems) }\end{array}$ & 4.3.1 Number of energr conversion systems or industrial applications \\
\hline & \multirow{2}{*}{$\begin{array}{l}\text { 4.4 R\&D required before } \\
\text { demonstration reactor } \\
\text { construction/operation }\end{array}$} & 4.4.1 R\&D Fime \\
\hline & & 4.4.2R8D Cost \\
\hline & \multirow{2}{*}{$\begin{array}{l}\text { 4.5 Provide ability to conduct } \\
\text { irradiations of materials and fuels } \\
\text { under prototypical condinions }\end{array}$} & 4.5. 1 Flux Conditions (Fast and Thermal) \\
\hline & & 4.5. 2 Irradiation Volume and Length \\
\hline \multirow{3}{*}{$\begin{array}{l}\text { 5. Demonstration Fuel Crcle of } \\
\text { Advanced Reactor }\end{array}$} & 5.1 Prototypic fuel fabrication & S1.1 is the fuel fabrication appeoach prototypic of scalable to commercial unit? \\
\hline & 5.2 Prototypic fuel performance & 5.12 is anticipated fuel performance prototypic or scalable to commercial unit? \\
\hline & 5.35pent fuei handling. & 5.13 is the spent fuel handing prototypic or scalable to commercial unit? \\
\hline
\end{tabular}

Fig. A.2. Demonstration test reactor criteria/metrics.

\begin{tabular}{|c|c|c|c|c|}
\hline \multirow{2}{*}{\multicolumn{2}{|c|}{ Goal }} & \multicolumn{3}{|c|}{ Weighting against Strategic Objectives (\%) } \\
\hline & & 1 & 2 & 3 \\
\hline 1 & $\begin{array}{l}\text { Demonstration Reactor significantly advances } \\
\text { the technology toward a potential FOAK Plant }\end{array}$ & 20 & 15 & 35 \\
\hline 2 & $\begin{array}{l}\text { Demo reactor operations help resolve technical } \\
\text { barriers (e.g., predictability) to advance reactor } \\
\text { economics and reliability }\end{array}$ & 30 & 25 & 15 \\
\hline 3 & $\begin{array}{l}\text { Demonstration Reactor has a robust Safety } \\
\text { Design Basis for licensing }\end{array}$ & 20 & 15 & 20 \\
\hline 4 & $\begin{array}{l}\text { Demonstration Reactor supports demonstration } \\
\text { of technology and system integration } \\
\text { (enhancing immediate, intermediate and long- } \\
\text { term value of the project) }\end{array}$ & 20 & 15 & 20 \\
\hline 5 & Demonstrate Fuel Cycle of Advanced Reactor & 10 & 30 & 10 \\
\hline
\end{tabular}

Fig. A.3. Demonstration test reactor strategic objective goal weight functions. 


\begin{tabular}{|c|c|c|c|c|}
\hline \multicolumn{2}{|r|}{ Goal } & \multirow{2}{*}{\begin{tabular}{|c|} 
Criteria \\
1.1 \\
\end{tabular}} & & \multirow{2}{*}{\begin{tabular}{|c|} 
Weighting within Goal (\%) \\
35 \\
\end{tabular}} \\
\hline \multirow{5}{*}{1} & \multirow{5}{*}{$\begin{array}{l}\text { Demonstration Reactor significantly advances } \\
\text { the technology toward a potential FOAK Plant }\end{array}$} & & $\begin{array}{l}\text { Capability to demonstrate safety behavior } \\
\text { of commercial system }\end{array}$ & \\
\hline & & 1.2 & $\begin{array}{l}\text { Detailed instrumentation and data for code } \\
\text { validation tests }\end{array}$ & 15 \\
\hline & & 1.3 & Scalable technology options & 20 \\
\hline & & 1.4 & $\begin{array}{l}\text { Scalable maintenance techniques and } \\
\text { schedules }\end{array}$ & 15 \\
\hline & & 1.5 & Scalable fabrication options & 15 \\
\hline \multirow{2}{*}{2} & \multirow{2}{*}{$\begin{array}{l}\text { Demo reactor operations help resolve technical } \\
\text { barriers (e.g., predictability) to advance reactor } \\
\text { economics and reliability }\end{array}$} & 2.1 & Construction Costs and Schedule & 50 \\
\hline & & 2.2 & Operational Costs & 50 \\
\hline 3 & $\begin{array}{l}\text { Demonstration Reactor has a robust Safety } \\
\text { Design Basis for licensing }\end{array}$ & 3.1 & $\begin{array}{l}\text { Licensed by the Nuclear Regulatory } \\
\text { Commission }\end{array}$ & 100 \\
\hline \multirow{5}{*}{4} & \multirow{5}{*}{$\begin{array}{l}\text { Demonstration Reactor supports demonstration } \\
\text { of technology and system integration } \\
\text { (enhancing immediate, intermediate and long- } \\
\text { term value of the project) }\end{array}$} & 4.1 & Facilitate component demonstration & 35 \\
\hline & & 4.2 & $\begin{array}{l}\text { Demonstrate alternate core configurations } \\
\text { and fuel types }\end{array}$ & 20 \\
\hline & & 4.3 & $\begin{array}{l}\text { Demonstrate integration with various } \\
\text { energy conversion systems or industrial } \\
\text { applications }\end{array}$ & 10 \\
\hline & & 4.4 & $\begin{array}{l}\text { R\&D required before demonstration } \\
\text { reactor construction/operation }\end{array}$ & 20 \\
\hline & & 4.5 & $\begin{array}{l}\text { Provide ability to conduct irradiations of } \\
\text { materials and fuels under prototypical } \\
\text { conditions. }\end{array}$ & 15 \\
\hline \multirow{3}{*}{5} & \multirow{3}{*}{ Demonstrate Fuel Cycle of Advanced Reactor } & 5.1 & Prototypic fuel fabrication & 35 \\
\hline & & 5.2 & Prototypic fuel performance & 35 \\
\hline & & 5.3 & Spent fuel handling & 30 \\
\hline
\end{tabular}

Fig. A.4. demonstration test reactor criteria weight functions. 
Design options and their associated issues are identified and tracked in the DecisionMatrix spreadsheet (Fig. A.4). The number and consequence of issues are correlated to the TRLs as established by DOE (Fig. A.5). Along with an issue ID, the owner, status, and schedule for resolution are tracked (Figure A.4.a). Issues are correlated with the affected systems and metrics and are graded for consequence to generate an overall score (Fig. A.4b). Finally, issues are assessed against overall design risk and are targeted for resolution options (Fig. A.4c). Design risk is associated with probability of the issue impacting the achievement of target TRL for the system. This is tracked as the consequence, which includes a drop down menu for $0-100 \%$. These probabilities can correlate to the risk matrix in Fig. A.6.

\begin{tabular}{|c|l|l|l|l|l|}
\hline Add Task/Issue & & & & \\
\hline (T)ASK/(I)SSUE NUMBER TASK/ISSUE OWN DESCRIPTION STATUS N SCHEDULE & NOTES \\
\hline \multicolumn{2}{|l|}{ Hale } & Salt Freeze/Thaw & Issue Categorized & Phase II & Need to address \\
\hline
\end{tabular}

Fig. A.4a. Spreadsheet issue input (description/owner/schedule/notes).
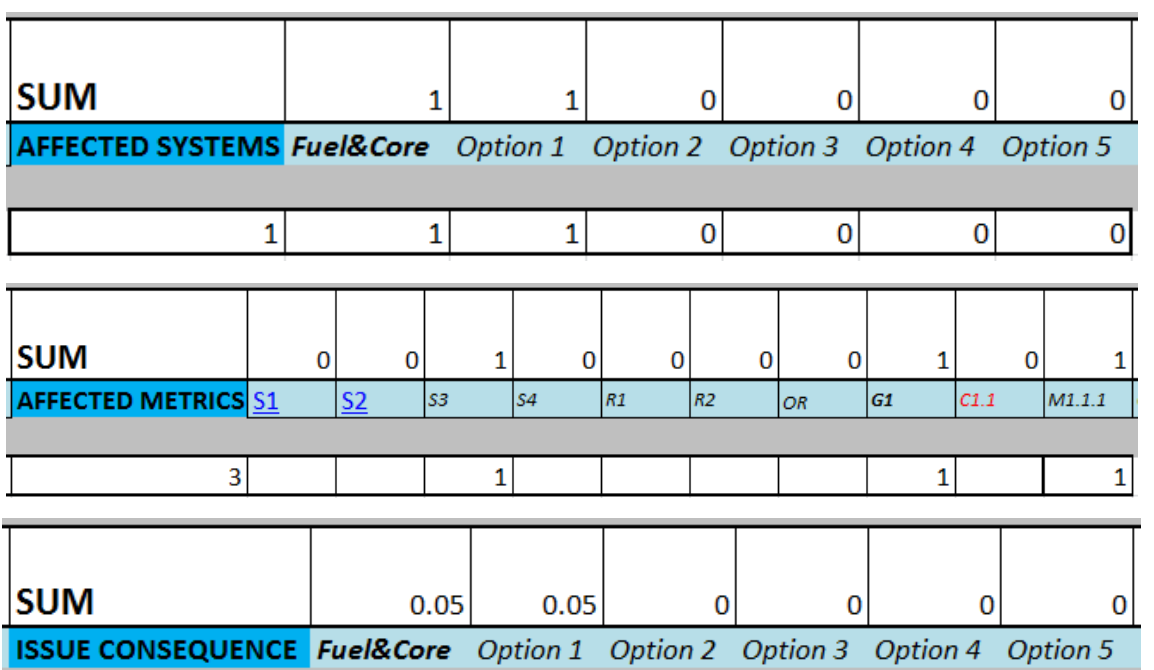

\begin{tabular}{|l|l|l|l|l|l|l|}
\hline 0.05 & 0.05 & 0.05 & & & & \\
\hline
\end{tabular}

\begin{tabular}{|c|c|c|c|c|c|c|}
\hline SUM & 0.04 & 0.04 & 0 & 0 & 0 & 0 \\
\hline ISSUE SCORE & Fuel\&Core & Option 1 & Option 2 & Option 3 & Option 4 & Option 5 \\
\hline 0.04 & 0.04 & 0.04 & 0 & 0 & 0 & 0 \\
\hline
\end{tabular}

Fig. A.4b. Spreadsheet issue input (affected systems/metrics/consequence/score)

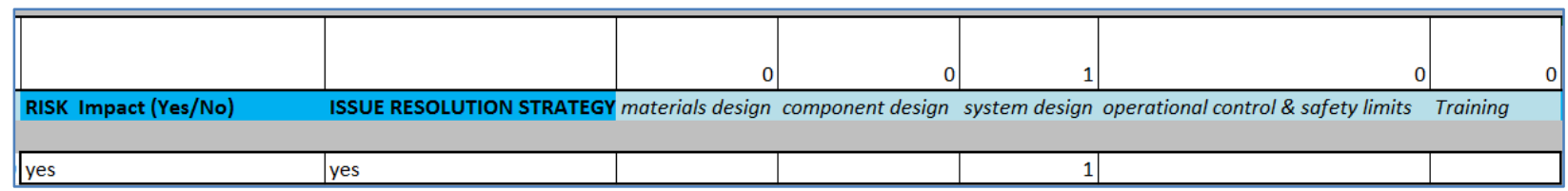

Fig. A.4c. Spreadsheet issue input (risk/issue resolution) 
Issues are summed and evaluated against the criteria for TRLs. These are then used to establish a baseline TRL at both the subsystem level and the overall integrated design level. As the end state of the reactor is not necessarily TRL 9, it is important to identify the target TRL levels for the systems and integrated overall design.
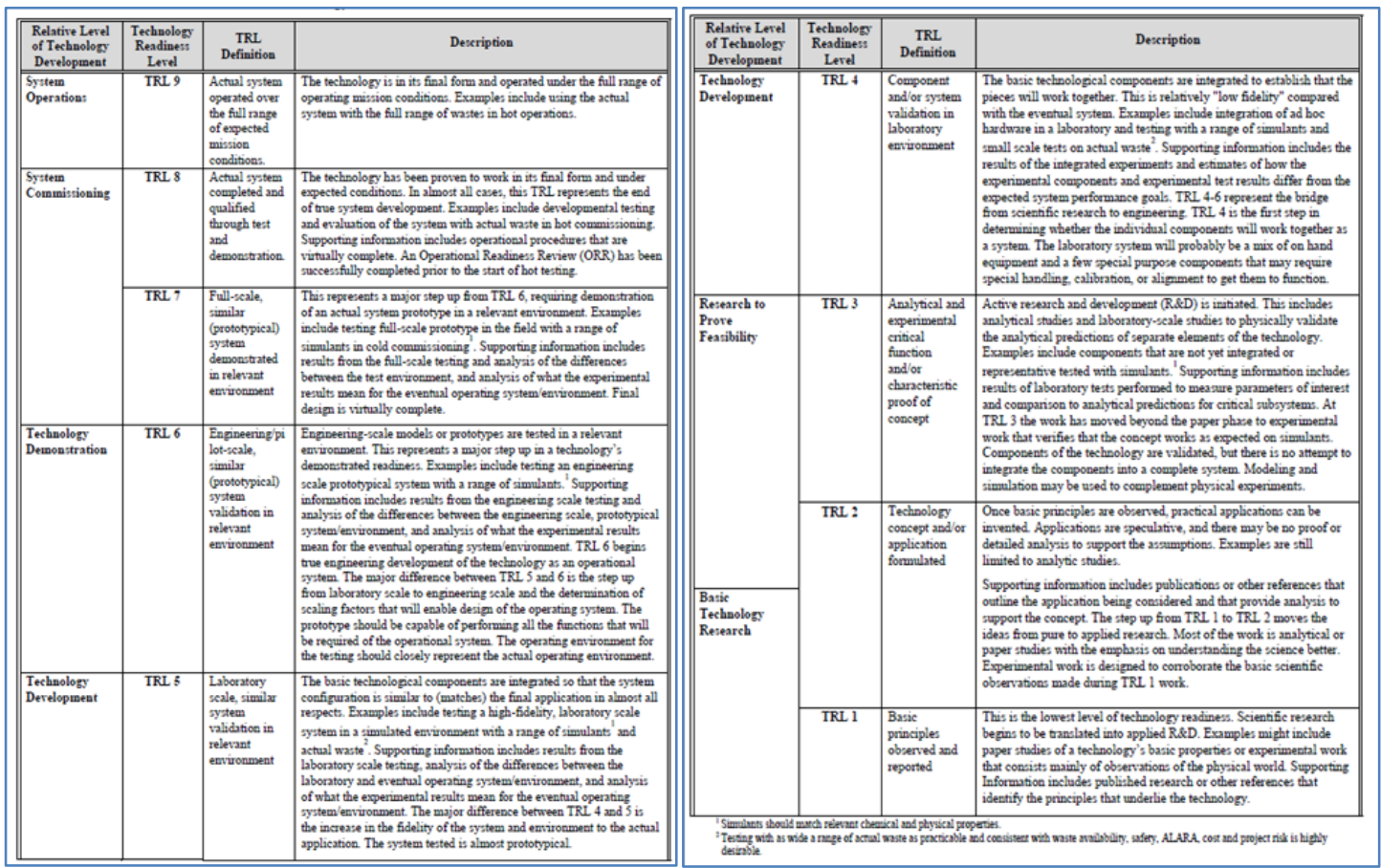

Figure A.5. DOE TRL levels. 


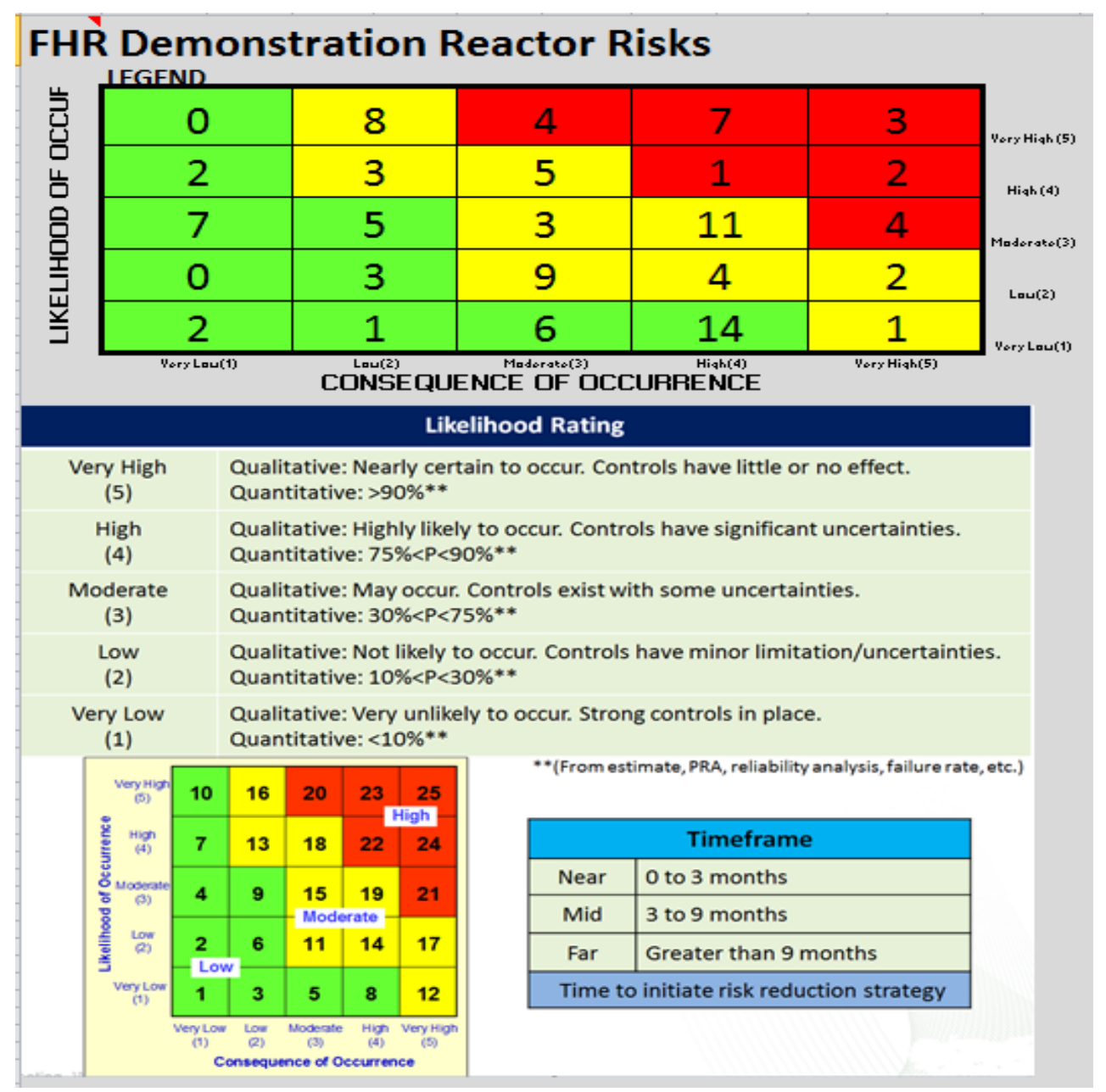

Fig. A.6. FHR risk matrix.

Once issues are identified and scored, they are used to adjust the initial baseline TRL level estimate (Fig. A.7), which is then used to update the overall metric scores for the systems and the overall integrated design.

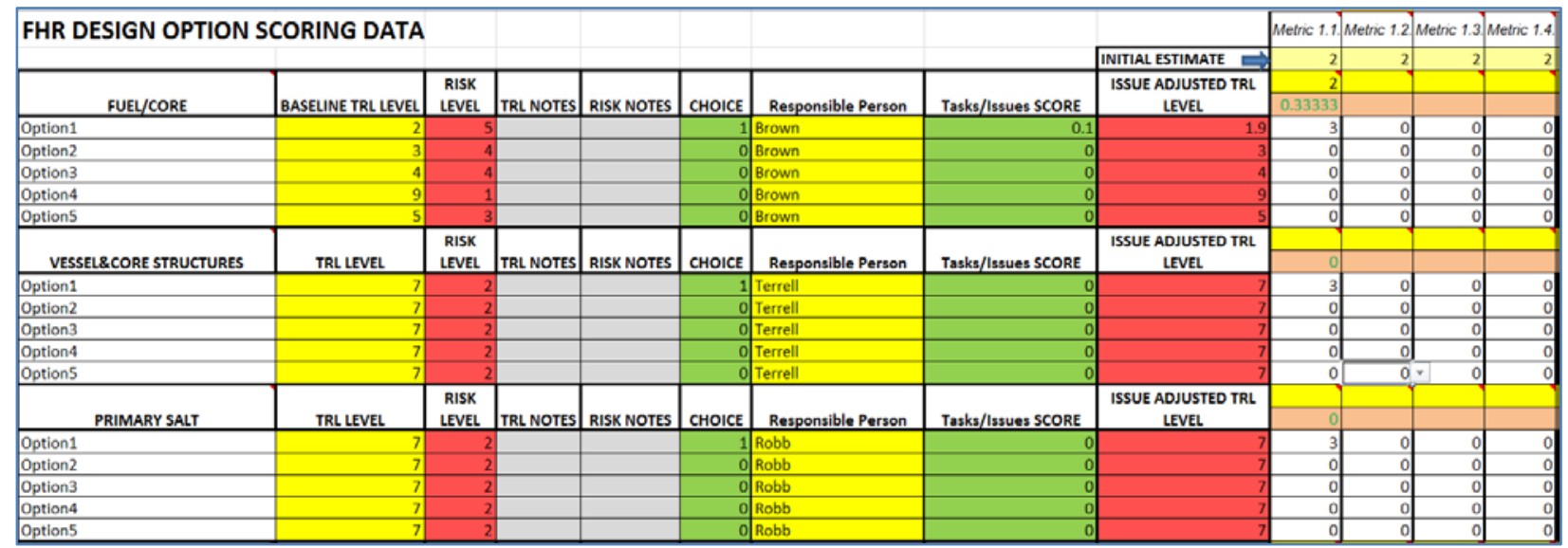

Fig. A.7. FHR scoring data input. 
Data in the scoring data sheet are used to output an estimate of the current design, analyzed design, and target design against the metrics. Fig. A.8 provides an example of this. Each subsystem is identified in the left column and across the top row. Selection of potential options in the second row is used to populate a "current TRL" in the second column. The "target TRL" is the end state goal. Between these two states (green cells indicate current, and red cells indicate target), the blank white cells are populated with the number of issues to be resolved to get to each successively greater TRL level (numbers in red). Under each TRL level column (1-9 in the third row), the goal, criteria and metric scores associated with that presumed TRL level for the overall design are established. This is used to determine the impact of the assumed overall TRL level on the system metric scores, which are then used as a guide for optimizing further development.

\begin{tabular}{|c|c|c|c|c|c|c|c|c|c|c|c|c|}
\hline FUEUCORE & VESSEL & PRIMARY SALT & \begin{tabular}{|l} 
INTERMED \\
IATE SALT \\
\end{tabular} & $\begin{array}{c}\text { PRIMARY } \\
\text { PIPINGIPUM } \\
\text { PING } \\
\end{array}$ & $\begin{array}{l}\text { INTERMMEDT } \\
\text { ATE } \\
\text { PIPINGIPUM }\end{array}$ & $\begin{array}{c}\text { SECDINDAR } \\
\mathbf{Y} \\
\text { PIPINGIPUM }\end{array}$ & \begin{tabular}{|c|} 
AUXX \\
SYSTEM \\
S
\end{tabular} & \begin{tabular}{|l|} 
CONFINE! \\
CONTAIN \\
\end{tabular} & \begin{tabular}{c|} 
SALT \\
CHEMISTRYIC \\
LEANUP \\
\end{tabular} & $\begin{array}{c}\text { TISTREUMENTI } \\
\text { ATION } \\
\text { CONTROL } \\
\end{array}$ & SAFETY & \begin{tabular}{c|} 
WASTIE \\
MGMTISPEN \\
T FUEL \\
\end{tabular} \\
\hline Option1 & Option2 & Option1 & Option4 & Option2 & Option2 & Option2 & Option2 & Option2 & Option2 & Option2 & Option2 & Option2 \\
\hline System & Current TRL & Analyzed TRL & Target TRL & 9 & 8 & 7 & 6 & 5 & 4 & 3 & 2 & 1 \\
\hline FUEL/CORE & 4 & 5 & 9 & & - & 3 & 1 & 4 & & & & \\
\hline VESSEL\&CORE STRUCTURES & 7 & 5 & 8 & & & & & & & & & \\
\hline PRIMARY SALT & 4 & 5 & 8 & & & 7 & $\underline{2}$ & 10 & & & & \\
\hline \begin{tabular}{|l} 
INTERMEDIATE SALT \\
\end{tabular} & 3 & 5 & 9 & & 6 & 12 & 3 & 5 & 3 & & & \\
\hline PRIMARY HX/PIPING/PUMPING & $\frac{5}{5}$ & 5 & 9 & & 4 & 2 & 1 & & & & & \\
\hline INTERMEDIATE HX/PIPING/PUMPING & 5 & 5 & 8 & & & 5 & 9 & & & & & \\
\hline SECONDARY HX/PIPING/PUMPING & 8 & 5 & 9 & & & & & & & & & \\
\hline \begin{tabular}{|l} 
AUX. SYSTEMS \\
\end{tabular} & 8 & 5 & 9 & & & & & & & & & \\
\hline CONFINE/CONTAIN & 7 & 5 & 9 & & 11 & & & & & & & \\
\hline SALT CHEMISTRY/CLEANUP & 2 & 5 & 8 & & & 1 & 6 & 2 & 5 & 3 & & \\
\hline INSTRUMENTATION/CONTROL & 2 & 5 & 8 & & & 4 & 1 & 4 & 5 & 9 & & \\
\hline SAFETY & 4 & 5 & 正 & & & & 2 & 7 & & & & \\
\hline WASTE MGMT/SPENT FUEL & 2 & 5 & 8 & & & 5 & 2 & 8 & 11 & 14. & & \\
\hline GOAL SCORES / TC & OTAL SYS & TTEM TRL L & LEVEL $\Rightarrow$ & 9 & 8 & 7 & 6 & 5 & 4 & 3 & 2 & 1 \\
\hline GOAL \#1 & 2.2 & 2.1 & 2.9 & 3 & 2.45 & 2.3 & 2.1 & 1.8 & 1.75 & 1.65 & 1.4 & 1 \\
\hline \begin{tabular}{|l|} 
Criteria 1.1 \\
\end{tabular} & 0.7 & 0.7 & 0.7 & 1.05 & 0.7 & 0.7 & 0.7 & 0.35 & 0.35 & 0.35 & 0.35 & 0.35 \\
\hline Metric 1.1.1. & 2 & 2 & & 3 & & 2 & & & 1 & 1 & 1 & \\
\hline \begin{tabular}{|l|} 
Criteria 1.2 \\
\end{tabular} & 0.3 & 0.3 & 0.3 & 0.45 & 0.45 & 0.3 & 0.45 & 0.45 & 0.45 & 0.3 & 0.3 & 0.15 \\
\hline Metric 1.2.1 & 4 & 2 & 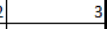 & 3 & 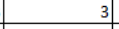 & 4 & 3 & 3 & 3 & 2 & 2 & \\
\hline \begin{tabular}{|c|} 
Criteria 1.3 \\
\end{tabular} & 0.6 & 0.6 & 0.6 & 0.6 & 0.4 & 0.4 & 0.2 & \begin{tabular}{l|l}
0.4 \\
\end{tabular} & 0.2 & 0.4 & 0.4 & 0.2 \\
\hline Metric 1.3.1 & 3 & 2 & 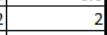 & 3 & 2 & 2 & 1 & 2 & 1 & 2 & 2 & \\
\hline \begin{tabular}{|c|} 
Criteria 1.4 \\
\end{tabular} & 0.3 & 0.3 & 0.3 & 0.45 & 0.45 & 0.45 & 0.3 & \begin{tabular}{l|l}
0.15 \\
\end{tabular} & 0.3 & 0.3 & 0.15 & 0.15 \\
\hline Metric 1.4.1 & 2 & 2 & & & & 3 & 2 & 1 & 2 & 2 & 1 & \\
\hline \begin{tabular}{|l|} 
Criteria 1.5 \\
\end{tabular} & 0.3 & 0.3 & 0.3 & 0.45 & 0.45 & 0.45 & 0.45 & \begin{tabular}{l|l}
0.45 \\
\end{tabular} & 0.45 & 0.3 & 0.15 & 0.15 \\
\hline \begin{tabular}{|l} 
Metric 1.5.1 \\
\end{tabular} & 2 & 2 & 2 & 3 & 3 & 3 & 3 & 3 & 3 & 2 & 1 & 1 \\
\hline
\end{tabular}

Fig. A.8. FHR scoring data input.

Data from these basic elements can be imported into various Excel add-ons for further optimization. Two of the add ons are Decision Suites TopRank ${ }^{\odot}$ and PrecisionTree ${ }^{\odot}$, both of which are discussed below as a means to direct and optimize the design process.

\section{Decision Tree Analysis}

Decision trees are useful for analyzing the impact of options on an overall design strategy. The PrecisionTree $^{\odot}$ is an example of such a tool. A decision tree has been created that allows for design review against the goals/criteria/metrics/ weighting functions to determine an overall design score. The basic elements of a decision tree include branch points, logic gates, probability estimates, and weighting factors.

The data that populates the DecisionMatrix spreadsheet is incorporated into an overall decision tree that assigns a SCORE value to design choices and propigates it through the decision tree to establish an overall integrated SCORE (Fig. A.9) and UNCERTAINTY values based on an assumed TRL level for the design choice. The ORNL concept is focused on Strategic Objective 3, and the overall weighting factors are applied throughout the decision tree at various levels (goals/criteria/metrics) as seen in Figs. A.2-A.4. 
The decision tree includes consideration of the impact of various aspects of the design (i.e., fuel/core, salt, vessel, etc.) and design choices on the overall design grade score. The initial values and score are representative samples that will be refined and updated at various stages and phases of the design process. This process is important, as individual goal/criteria optimizations may be in conflict and require trade study. The use of this decision tree will provide guidance to help ensure overall design optimization within the given constraints to meet the overall strategic objective.

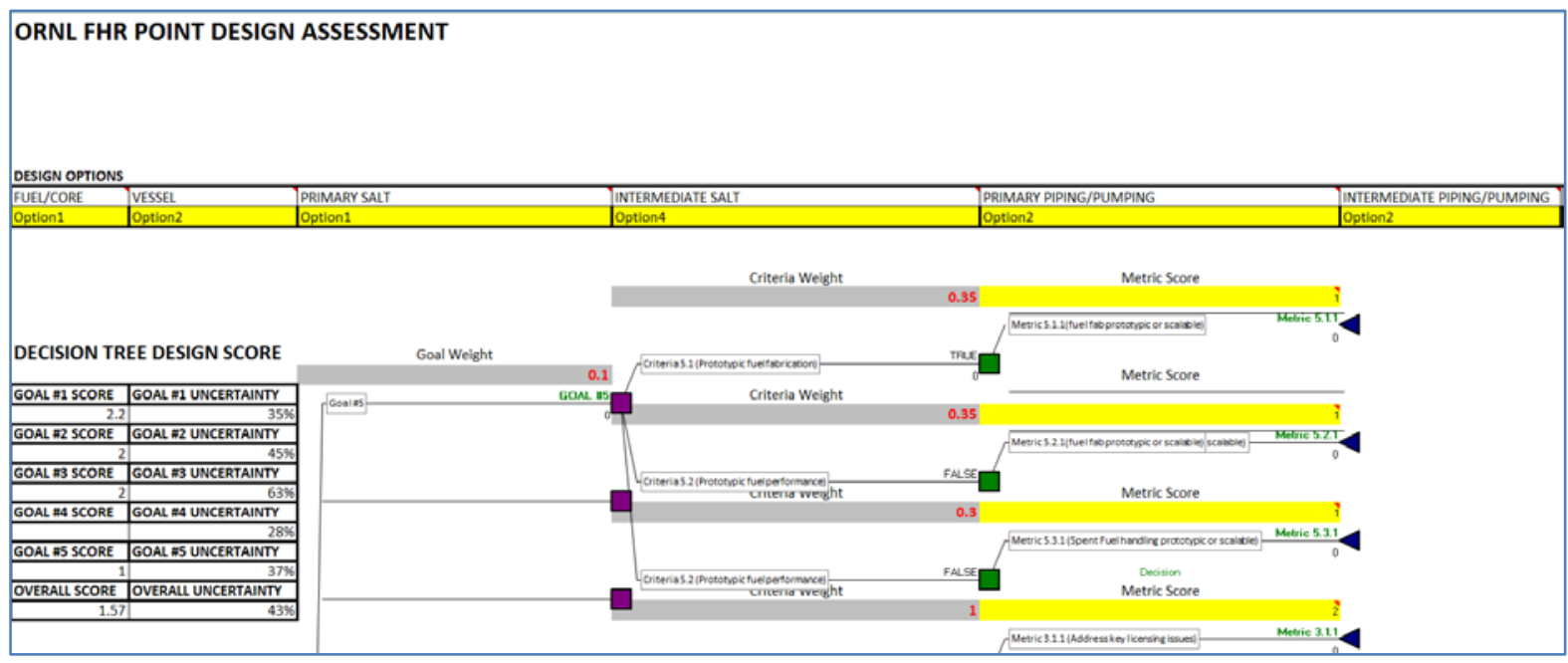

Fig. A.9. Example DecisionMatrix spreadsheet decision tree.

\section{Sensitivity Analysis}

In parallel with data input, an analysis can be performed to determine the sensitivity of the design to system optimization. For example, the fuel/core system's impact on the overall design metrics could be significantly greater than that associated with the secondary cooling loop. In this case, more time and effort should be spent resolving issues in this area to maximize the potential overall score. The tool used to perform this analysis is Decision Suites Top Rank. Although it is not yet adopted into the FHR DR DecisionMatrix spreadsheet framework, examples of a tornado plot and a spider plot that can be used to prioritize inputs (system TRLs) for their impact on the overall design score are shown in Figs. A.10 and A.11. The inputs will be the systems (i.e., fuel/core, primary salt, etc.) denoted on the y axis (here seen as unit sales price, etc.), and the impact on the outputs will be the overall design metric score. These types of outputs would be used to prioritize the areas of design focus needed to maximize the overall score. 


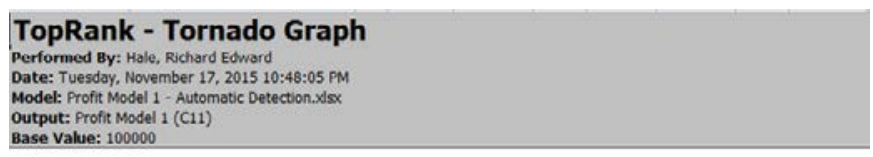

Base Value: 100000

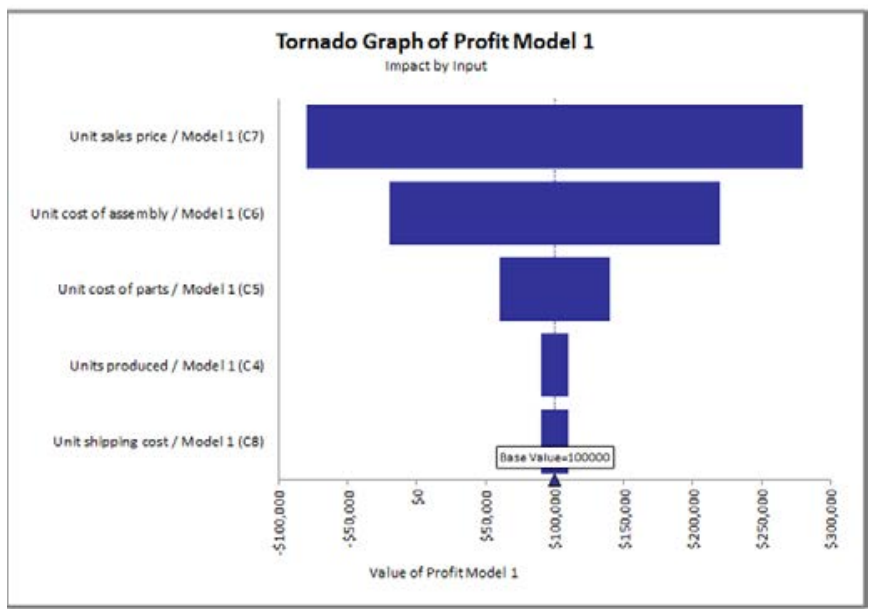

Fig. A.10. Example Top Rank Tornado plot based on the Figures of Merit. 


\section{TopRank - Spider Graph}

Performed By: Hale, Richard Edward

Date: Tuesday, November 17, 2015 10:48:05 PM

Model: Profit Model 1 - Automatic Detection.xlsx

Output: Profit Model 1 (C11)

Base Value: 100000

\section{Spider Graph of Profit Model 1}

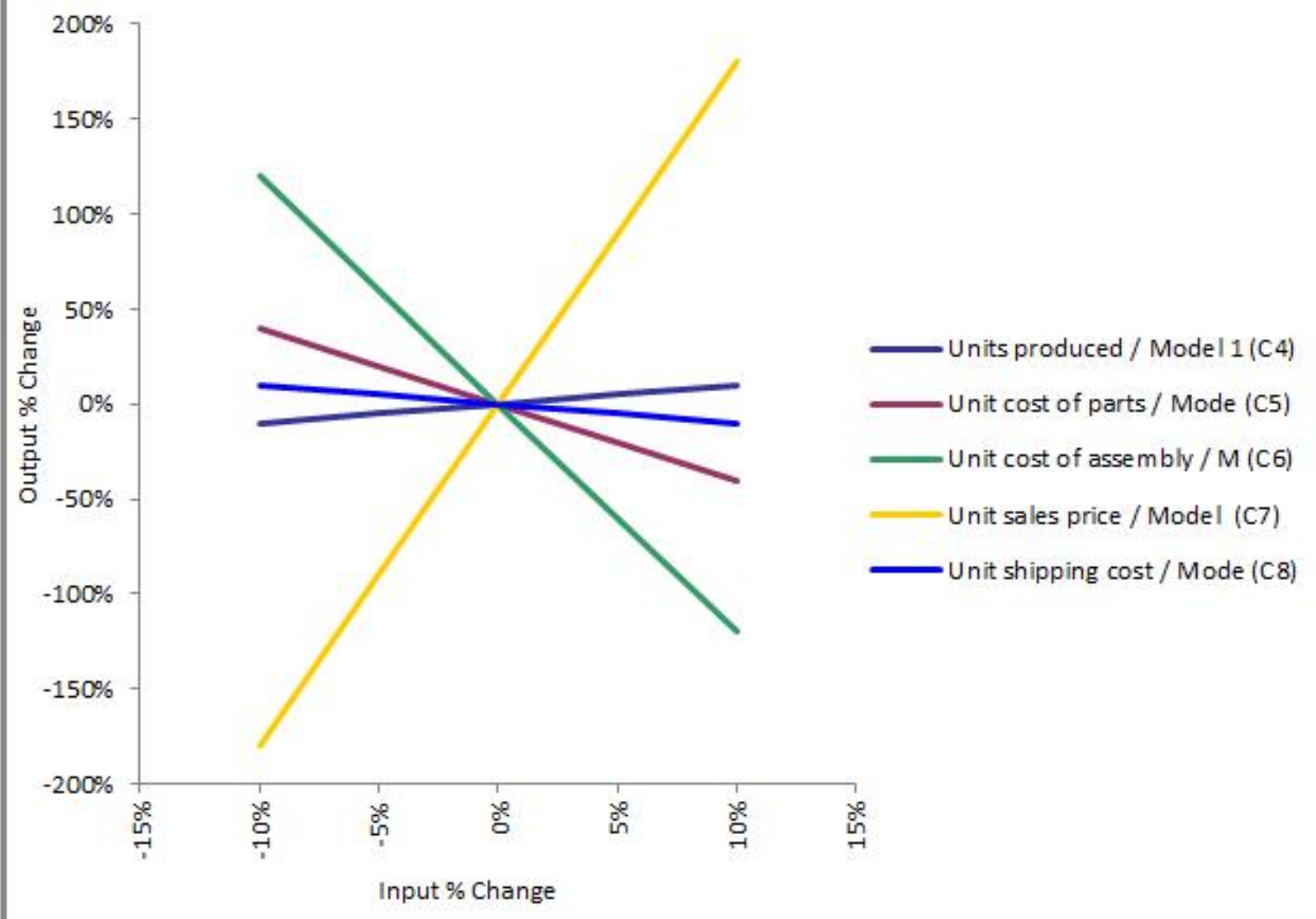

Fig. A.11. Example TopRank Spider graph based on the Figures of Merit. 